6-1-1969

\title{
An Investigation of a Structural Model of Small Group Problem Solving
}

David Dwight Harshbarger

How does access to this work benefit you? Let us know!

Follow this and additional works at: https://commons.und.edu/theses

\section{Recommended Citation}

Harshbarger, David Dwight, "An Investigation of a Structural Model of Small Group Problem Solving" (1969). Theses and Dissertations. 3698.

https://commons.und.edu/theses/3698

This Dissertation is brought to you for free and open access by the Theses, Dissertations, and Senior Projects at UND Scholarly Commons. It has been accepted for inclusion in Theses and Dissertations by an authorized administrator of UND Scholarly Commons. For more information, please contact und.commons@library.und.edu. 
AN INVESTIGATION OF A STRUCTURAL MODEL OF SMALL GROUP PROBLEM SOLVING

$$
\text { by }
$$

David Dwight Harshbarger

A.B., West Virginia University 1960

M.A., West Virginia University 1961

\author{
A Dissertation \\ Submitted to the Faculty \\ of the \\ University of North Dakota \\ in partial fulfillment of the requirements \\ for the degree of \\ Doctor of Philosophy
}

Grand Forks, North Dakota 
This dissertation submitted by David Dwight Harshbarger in partial fulfillment of the requirements for the Degree of Doctor of Philosophy from the University of North Dakota is hereby approved by the Faculty Advisory Committee under whom the work has been done.
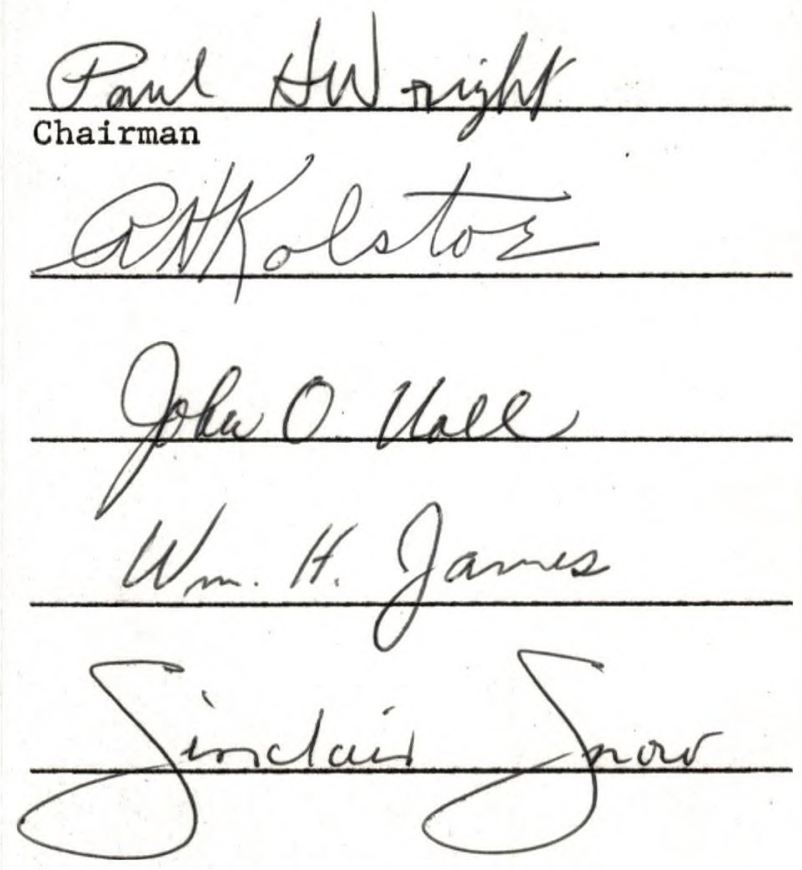

Dean of the Graduate School 
Permission

AN INVESTIGATION OF A STRUCTURAL MODEL OF SMALL GROUP

Title PROBLEM SOLVING

Department

Psychology

Degree

Doctor of Philosophy

In presenting this dissertation in partial fulfillment of the requirements for a degree from the University of North Dakota, I agree that the Library of this University shall make it freely available for inspection. I further agree that permission for extensive copying of this dissertation for scholarly purposes may be granted by the professor who supervised my dissertation work, or, in his absence, by the Chairman of the Department or the Dean of the College in which my dissertation work was done. It is understood that any copying or publication or other use of this dissertation or part thereof for financial gain shall not be allowed without my written permission. It is also understood that due recognition shall be given to me and to the University of North Dakota in any scholarly use which may be made of any material in my dissertation.

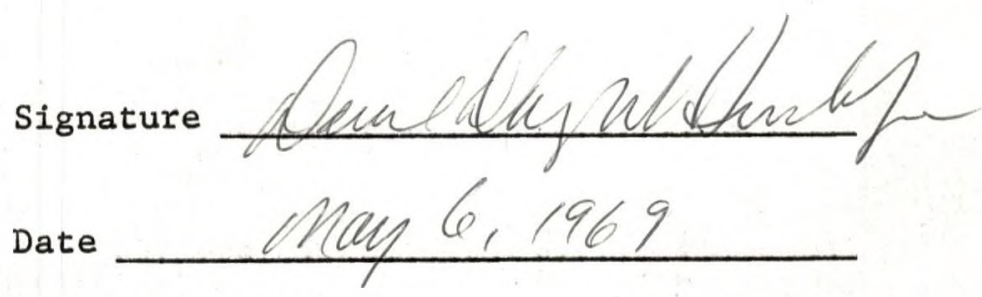




\section{ACKNOWLEDGMENTS}

The writer wishes to express his appreciation to his committee chairman, and advisor, Dr. Paul Wright, for his generous contribution of time and effort to the completion of this study. Appreciation is also extended to the other members of the committee, Dr. Ralph Kolstoe, Dr. William James, Dr. John Noll, and Dr. Sinclair Snow. The personal and financial support of the New School of Behavioral Studies in Education during the 1968-69 academic year is deeply appreciated. In particular, the writer would like to thank Dean Vito Perrone for his encouragement during the course of this research.

Finally, a very special expression of gratitude is extended to my wife Emily, and our son David, whose sacrifices and support have sustained my graduate studies. 
TABLE OF CONTENTS

Page

ACKNOWLEDGMENTS ....................... iv

LIST OF TABLES . . . . . . . . . . . . . . . . . . . vi vi

LIST OF FIGURES . . . . . . . . . . . . . . . . . . vii vi vi vi

ABSTRACT . . . . . . . . . . . . . . . . . viii

Chapter

I. INTRODUCTION . . . . . . . . . . . . . . . I I

The Conceptual Model

Hypotheses

II. METHOD . . . . . . . . . . . . . . . . . .

Apparatus

Construction of Experimental Conditions

III. RESULTS . . . . . . . . . . . . . . . . . .

Treatment of the Data

The Congruence Model and Indices of Group

Process

The Congruence Model and Outcomes

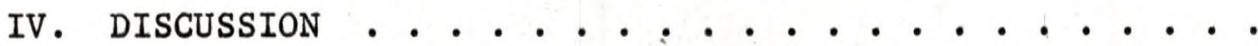

APPENDIX . . . . . . . . . . . . . . . . . . . .

REFERENCES . . . . . . . . . . . . . . . . . . . 
LIST OF TABLES

Table

Page

1. Synopsis of Communication-Network Findings . . . . . .

2. Number of Information Transactions to Solution, Type of Group Structure by Position

(Transformed Data) . . . . . . . . . . . .

3. Number of Information Transactions to Solution, Type of Group Structure by Problem

(Transformed Data) . . . . . . . . . . . .

4. Solution Time, Type of Group Structure by Problem

(Transformed Data) . . . . . . . . . . .

5. Leader Nominations Under Conditions of High and Low Decision Centrality . . . . . . . . . . .

6. Accuracy of Solutions to Problems 1-3 . . . . . . . .

7. Rated Effectiveness of Problem Solving, by Type of Group Structure (Transformed Data)

8. Rated Effectiveness of Problem Solving, Type of Group Structure by Position (Transformed Data) . . . .

9. Rated Satisfaction, Type of Group Structure by Problem (Transformed Data) . . . . . . . . . .

10. Rated Satisfaction, Type of Group Structure by

Position (Transformed Data) 
LIST OF FIGURES

Figure

Page

1. Communication networks in 4 person groups. Circles represent positions, lines represent communication channels... . . . . . . . . . . . . .

2. Decision and interaction structures in 4 person groups. The circles represent positions, lines represent communication channels, and $\mathrm{x}$ 's represent decision maker positions . . . . . . . . .

3. Log of number of information transactions for the interaction of group position and the conditions of interaction centrality . . . . . . . . . . .

4. Log of the number of information transactions for the interaction of decision and interaction centrality . . .

5. Log of the number of information transactions to solution for the interaction of the conditions of group structure across problems . . . . . . . .

6. Log of number of information transactions to solution for each problem under the conditions of structural congruence . . . . . . . . . . . . . . . .

7. Log number of seconds to solution for the interaction of the conditions of group structure . . . . . . . .

8. Contrast of rated effectiveness and number of correct solutions under conditions of decision centrality . . .

9. Log of rated problem solving effectiveness for interaction of position and decision centrality . . . . 


\section{ABSTRACT}

Past research on the nature of small group problem solving has led to contradictory findings. Using complex problems, Shaw (1954b) found a decentralized interaction structure, i.e., a group arrangement in which group members can communicate freely, to be most effective in reaching accurate solutions. Mulder (1960), using Shaw's complex problems, found a centralized decision structure, i.e., a group arrangement in which decisions were made by a small proportion of group members, to be most effective in reaching accurate solutions. Hutte (1965), suggested greater accuracy was found when a decentralized decision structure was used in complex problem solving. In none of these studies was there an independent and systematic treatment of the effects of decision and interaction structures.

The present study was conducted to test a proposed structural model of small group problem solving. The model, derived largely from the research of Bales (1950), and the theoretical work of Homans (1961), suggests that accuracy of problem solving and indices of group process will vary as a function of the interaction and decision structures. It was hypothesized that the degree of congruence between the centrality of the decision and interaction structures would be reflected in indices of group process and problem solving outcomes.

There were 4 conditions of structural congruence: 1) decision centrality high, interaction centrality high; 2) decision centrality 
high, interaction centrality low; 3) decision centrality low, interaction high; 4) decision centrality low, interaction centrality low. Conditions 1 and 4 were described as structurally congruent, and conditions 2 and 3 were described as structurally incongruent. Under each of these conditions, 6 groups, each composed of 4 Ss, solved 3 complex problems.

Statistically significant interactions for the conditions of decision and interaction centrality supported the proposed structural model. The congruence of the decision and interaction structures was reflected in both time and number of information transactions required to reach the solution to each problem.

Support for the model was not found in the problem solving outcomes of accuracy of problem solving, perceived effectiveness of problem solving, and subjective satisfaction. Contrary to both Shaw and Mulder's research, groups with decentralized decision structures were found to be more accurate in their problem solutions. However, Ss perceived a centralized decision structure as more effective in solving problems. Subjective satisfaction was highest within a centralized interaction structure.

Based on the findings of this study, it might be generally predicted that a group which contains a decentralized decision structure will be more accurate in solving complex problems than a group with a centralized decision structure. If the dimension of a decentralized interaction structure is added to this group, the participants will, in all probability, like their task more than if the interaction structure is relatively centralized. Predictions 
regarding time and number of information transactions to solution will be most accurately made in terms of the combinations of conditions of decision and interaction structures. The Ss will bring into the group setting certain pressures and preferences for a centralized decision structure. If allowed a choice, a centralized decision structure will probably be the result, with such a choice leading to a relatively inaccurate performance. 


\section{CHAPTER I}

\section{INTRODUCTION}

For the past 20 years studies of the effects of communication patterns on performances of small groups have, collectively, comprised one of the more productive research areas in social psychology. Efforts to understand significant dimensions of group problem solving have typically employed the communication model developed by Bavelas (1948) and Leavitt (1951). In this model, small groups are required to solve problems within pre-established communication networks, e.g., position $\mathrm{A}$ and $\mathrm{B}$ share a communication channel, positions $\mathrm{A}$ and $\mathrm{C}$ share a communication channel, but $B$ and $C$ can communicate only through A. Variations in the model have resulted in a nomenclature which has attained considerable generality of usage in small group literature, and is indicated in Figure 1.

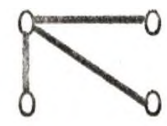

Star or Wheel

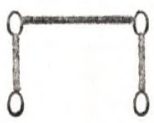

Chain

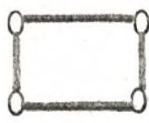

Circle

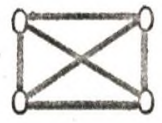

Comcon or All Channel

Fig. 1. Communication networks in 4 person groups. Circles represent positions, lines represent communication channels.

Most studies have isolated Ss from each other through the use of partitions, and have permitted only written or electrical transmission of information between positions. 
The problems investigated have traditionally been dichotomized as simple or complex, with research findings depending, in part, upon which type problem was employed. A simple problem, sometimes referred to as a Leavitt-type problem, is as follows:

To each S, labeled by color, is given a card on which there appears a set of five symbols. Each S's card is different from all the others in that the symbol lacking, the sixth one, is a different symbol in each case. Thus in any set of five cards there is only one symbol in common. The problem is for every member to find the common symbol (Leavitt, 1951, p. 41).

A complex problem requires that the Ss engage both in more sophisticated cognitive activities and a greater frequency and variety of information transmission than does the simple problem. The following is an example:

A small company is moving from one office building to another. It must move four kinds of equipment: chairs, desks, filing cabinets, and typewriters. How many trucks are needed to make the move in one trip?

Items :

Each truck will carry 12 typewriters and nothing else.

The company owns a total of 15 filing cabinets.

The company owns a total of 12 typewriters.

Each truck will carry 5 filing cabinets and nothing else.

Each truck will carry 24 chairs and nothing else.

The company owns a total of 48 chairs.

The company owns a total of 12 desks.

Each truck will carry 3 desks and nothing else. Answer: 10 trucks. A copy of the problem is given to each S. The items of information are equally and randomly distributed among Ss.

Table 1 contains a synopsis of communication network findings. While there is no unanimity regarding the relative effectiveness of various networks, reviews of the literature (Shaw, 1964; Jones and Gerard, 1967) have generally held that centralized communication channels (e.g. wheel) will lead to more effective problem solution with 
TABLE 1

SYNOPSIS OF COMMUNICATION-NETWORK FINDINGS

\begin{tabular}{|c|c|c|c|c|}
\hline Author & Date & $\begin{array}{r}\text { Group } \\
\text { size }\end{array}$ & $\begin{array}{l}\text { Network solution rate } \\
\text { (in descending order) }\end{array}$ & Task \\
\hline Leavitt & 1951 & 5 & Wheel (fastest tria1) & Simple \\
\hline $\begin{array}{l}\text { Heise and } \\
\text { Miller }\end{array}$ & 1951 & 3 & $\begin{array}{l}\text { A11-channe1: Wheel: Circle } \\
\text { Wheel: Al1-channel: Circle }\end{array}$ & $\begin{array}{l}\text { Simple } \\
\text { Complex }\end{array}$ \\
\hline Hirota & 1953 & 5 & No significant difference & Simple \\
\hline Shaw & $1954 a$ & 4 & No significant difference & Complex \\
\hline Shaw & $1954 b$ & 3 & $\begin{array}{l}\text { No significant difference } \\
\text { No significant difference }\end{array}$ & $\begin{array}{l}\text { Complex } \\
\text { Simple }\end{array}$ \\
\hline $\begin{array}{l}\text { Guetzkow and } \\
\text { Simon }\end{array}$ & 1955 & 5 & $\begin{array}{l}\text { Wheel: All-channel: Circle } \\
\text { (stable nets--no signif.diff.) }\end{array}$ & Simple \\
\hline Shaw & 1956 & 4 & All-channel: Wheel & Complex \\
\hline $\begin{array}{l}\text { Shaw and } \\
\text { Rothschild }\end{array}$ & 1956 & 4 & Al1-channe1: Whee1 & Complex \\
\hline $\begin{array}{l}\text { Guetzkow and } \\
\text { Dill }\end{array}$ & 1957 & 5 & All-channel: Circle & Simple \\
\hline $\begin{array}{l}\text { Shaw, Rothschild } \\
\text { and Strickland }\end{array}$ & 1957 & 4 & Al1-channe1: Whee1 & Complex \\
\hline Shaw & 1958 & 4 & Al1-channel: Wheel & Complex \\
\hline Mulder & 1959 & 4 & Whee1 & Simple \\
\hline Mulder. & 1960 & 4 & $\begin{array}{l}\text { No significant difference } \\
\text { No significant difference }\end{array}$ & $\begin{array}{l}\text { Simple } \\
\text { Complex }\end{array}$ \\
\hline $\begin{array}{l}\text { Mohanna and } \\
\text { Argyle }\end{array}$ & 1960 & 5 & Wheel & Simple \\
\hline $\begin{array}{l}\text { Cohen, Bennis } \\
\text { and Wolkon }\end{array}$ & 1961 & 5 & Wheel & Simple \\
\hline $\begin{array}{l}\text { Cohen, Bennis } \\
\text { and Wolkon }\end{array}$ & 1962 & 5 & Whee1 & Simple \\
\hline
\end{tabular}


TABLE 1--Continued

\begin{tabular}{lccccc}
\hline \hline Duthor & Date & $\begin{array}{c}\text { Group } \\
\text { size }\end{array}$ & $\begin{array}{c}\text { Network solution rate } \\
\text { (in descending order) }\end{array}$ & Task \\
\hline Lawson & $1964 \mathrm{a}$ & 4 & $\begin{array}{l}\text { (NR) All-channel, Wheel: Circle } \\
\text { (R) Wheel, All-channel: Circle }\end{array}$ & Simple \\
Lawson & $1964 \mathrm{~b}$ & 4 & $\begin{array}{l}\text { (NR) All-channel: Circle: Wheel } \\
\text { (R) All-channel, Circle: Wheel }\end{array}$ & Complex \\
Burgess & 1968 & 4 & $\begin{array}{l}\text { (NR) Wheel: Circle } \\
\text { (R) No Significant difference }\end{array}$ & Simple \\
\hline
\end{tabular}

a $N R=$ nonreinforced; $R$ = reinforced .

simple problems; decentralized communication channels (e.g., circle or all channel) will lead to more effective problem solution with complex problems.

In the early years of communication-problem solving research there was considerable interest in the study of the feelings of satisfaction and dissatisfaction in participants following their completion of problem solutions. Satisfaction was found to be relatively higher among participants who had occupied positions of centrality in the net, such as the hub in the wheel net (Bavelas, 1950; Leavitt, 1951;

Christie et al., 1952). However, the research was conducted using simple problems. Shaw (1954b), using complex problems, found a reversal of the earlier satisfaction results. Shaw noted that satisfaction needed to be interpreted in terms of both the centralization of the communication net and the type problem. He agreed with Bavelas, Leavitt, et al. that satisfaction would be higher among participants 
when a simple problem was solved by a highly centralized group. However, Shaw found that when a complex problem was solved by a highly centralized group, rated satisfaction was lower than among participants in a decentralized group.

A model has been developed (Leavitt, 1951; Shaw, 1954a) which is based on the concepts of independence and saturation. Independence refers to the extent to which a position in a communication network has restrictions on its freedom of action. As developed by Leavitt and Shaw, positions of low independence, with restrictions on freedom of action, result in frustration of personal needs for autonomy. Consequently, a position such as the hub position in the wheel net, one which might be described as having maximal freedom of action, would be a position in which a participant would feel considerable satisfaction.

The concept of saturation, developed by Gilchrist et al. (1954), refers to the information input or output requirements of a net position. A position is said to be saturated when its efficiency of operation is impeded by an overload of incoming messages, or a necessity to communicate too rapidly with other participants. The most central position, or hub, which is high in independence, would be unlikely to be saturated when a simple problem was being solved. However, if a complex problem were to be introduced, the hub position might become saturated with input and output demands, only some of which could be met. This would lead to feelings of frustration and dissatisfaction in occupants of the hub position. Because of these factors, Gilchrist argues, a centralized net such as the wheel is 
not as effective in solving complex problems as a less centralized net.

Gilchrist notes that groups organized around decentralized communication nets, whether working with simple or complex problems, are not likely to overload or saturate any single position. Participants in each position have the opportunity to act on each problem, or, to exercise independence. Consequently, both feelings of satisfaction and effectiveness of problem solving would be greater in less centralized nets when the groups are solving complex problems.

Others have indicated some support for Gilchrist's position regarding the relationship between satisfaction and independence. Maier and Hoffman $(1960,1962)$ found satisfaction to be positively correlated both with group decision making, and the degree of influence the participant had over the final decision.

A conceptual model for group problem solving which is almost entirely based on the nature of the interaction structure has come under some criticism from Mulder (1960). The crux of Mulder's criticism is that researchers have taken perhaps too shallow a view of what is occurring within the communication nets. More specifically, Mulder argues that too much emphasis has been placed on the topological structure of communication nets. The topological or structural characteristics of the nets do not really determine what occurs. Rather, the structural arrangement of the communication channels establishes limits or parameters within which a decision structure emerges. Mulder defines decision structure as "who makes decisions for whom," and hypothesizes that within any group a centralized decision structure 
must emerge if that group is to effectively and efficiently solve problems. Thus, whether a circle (decentralized net) or wheel (centralized net) is used as an interaction system, it serves only as a point of departure from which a decision structure emerges. A decision structure may emerge more rapidly from the wheel as opposed to the circle, but over a period of time decision structures of similar effectiveness will emerge from both. Visible differences in the effectiveness of problem solving of circle and wheel nets disappear as both nets reach roughly equivalent plateaus of problem solving performance. Recent findings reported by Burgess (1968), while focusing on reinforcement contingencies in small group problem solving, rather than the emergence of decision structures, also indicate that circlewheel net differences in problem solving effectiveness disappear over trials, and a "steady state" of performance occurs.

Thus, as researchers have focused on the dimensions within and surrounding communication nets, numerous factors of considerable complexity and importance have become visible. For the early communication net researchers such as Leavitt et al. the communication channel structure determined whatever level of performance occurred. Generally a relatively less effective performance was expected when a decentralized net solved a problem. In later research this was true only for relatively simple problems. These performances by respective nets were expected to occur consistently, over trials. Steady states of performances would occur, but at differing levels of effectiveness. Later researchers, Mulder and Burgess, assert that steady states emerge in problem solving performances of groups, these plateaus 
arising both through the emergence of a centralized decision structure, even within a decentralized net, and reinforcement contingencies surrounding problem solving.

Burgess' treatment of the reinforcement contingencies which affect group processes would seem to give some stability to those aspects of a conceptual model of group problem solving which are concerned with external factors. Mulder's research would seem to place critical internal group processes within a workable conceptual model, one which moves beyond a simple topological conception of the problem solving process. However, recent findings raise some questions about Mulder's concept of an emergent centralized decision structure.

Hutte (1965), in an investigation of problem solving in an all channel net, found a negative correlation between the degree of centralization of decision making, and the effectiveness of the groups' problem solving. While these findings were obtained with a somewhat more complex problem and different communication structure (all channel net) than those in Mulder's investigations, they suggest conclusions which are contradictory to those of Mulder.

Summarized, the preceding review of the literature indicates the following:

1. Shaw, using Bavelas-Leavitt type communication nets, found that decentralized communication nets were more effective in solving complex problems than were centralized nets.

2. Mulder has indicated that the communication net is not the critical issue; rather, the focus must be placed on the decision structure which emerges within the topology of a communication net. From 
research with both centralized and decentralized nets, Mulder has concluded that in either case a centralized decision structure is necessary for effective problem solution.

3. Hutte has found that groups with centralized decision structures tended to be less effective in solving complex problems than groups with more decentralized decision structures.

The problematical and contradictory findings in the preceding may stem from a confusion of research strategies, and the need to articulate possible underlying structural aspects of communication and decision structures. Shaw, working with the Bavelas-Leavitt model, has been primarily concerned with problem solving as a function of the communication or interaction structures of small groups. Mulder and Hutte have concerned themselves with decision structures in small groups, and have done so under the conditions of differing interaction structures, with contradictory findings resulting. None of these researchers has articulated a research model which contains both interaction and decision structures as major components. Rather, their respective investigations have been based on primary concerns with each, but not both, of these dimensions.

A conceptual model which is concerned with an integrative treatment of both interaction and decision making systems might be helpful in understanding underlying processes in problem solving groups. A two dimensional theory of group process has precedence in small group literature. Investigations of leader roles in small groups have pointed to the importance of a two dimensional theory of group interaction. Largely under the leadership of Bales 
(1950, 1955, 1956, 1958; Bales and Slater, 1955; Borgatta and Bales, 1953; Slater, 1955) these investigations have led to the differentiation of two distinct types of leader roles. These roles, termed task and social-emotional specialists, have distinctive characteristics. The task specialist's role is one concerned with facilitating group problem solving, goal attainment, and designing decision making strategies. The social-emotional specialist's role is one concerned with social processes in the group, and means of facilitating interaction. According to Bales, these two specialized roles develop in the leadership of virtually all productive problem solving groups.

If Bales' research and theory is conceptualized as focusing on two basic components of group problem solving processes, rather than two specific types of roles, it bears considerable resemblance to the Shaw-Mulder research. That is, if a) rather than focusing on a socialemotional leader, the conceptual model is extended to an interaction system or structure, in which the social-emotional leader plays a primary role; and, b) rather than focusing on a task leader the model is extended to encompass a decision making system or structure, in which the task leader plays a primary role, then a two factor structural model of group problem solving begins to develop.

Other, perhaps more commonplace, observations of problem solving groups in everyday life also suggest that a two factor conceptual model of small groups might be appropriately applied. Members of decision making committees in the academic, business, and political worlds have often pointed to the problems created by these two structural aspects of small problem solving groups. For example, interaction 
might be highly centralized in a small number of the members of a committee. The decision structure of that committee, however, might be highly decentralized, requiring a majority vote or even consensus in order for the group to resolve a question or issue. Conversely, interaction might be decentralized, with all members participating in the discussion, but the decision structure highly centralized, with one or two members of the group making decisions. From anecdotal reports, subjective reactions to these kinds of situations, as well as the quality of productivity of the group, often vary as a function of the congruent or incongruent relationships between these two dimensions.

Similarly, many participants report varying reactions in situations in which there is a more congruent relationship between the interaction and decision structures in the group. For example, when a freedom of interaction exists, with most members of the group interacting with most other members, and when most or all the members have a voice in the decision making processes of the group (e.g, majority vote or consensus), feelings of satisfaction and the indices of productivity seem to be relatively higher than when there is an incongruous relationship between interaction and decision structures. Congruous relationships between interaction and decision structures in restricted communication nets, e.g., wheel, with centralized decision structures; e.g., I decision maker, also may lead to relatively satisfying, productive, relationships. For example, work details in the Armed Forces, athletic teams, and various committees. 
There is no body of information regarding theory and research on congruence between interaction and decision structures in small groups. However, congruence in other dimensions, particularly status, have been examined. Based largely on theories of cognitive consistency (Heider, 1946; Newcomb, 1953; Osgood and Tannenbaum, 1955; Festinger, 1957), studies of status congruence in small groups have indicated that varieties or problems, such as lowered morale and decrements in quality of problem solution, occur as a function of the status incongruence among participants (e.g., Adams, 1953; Exline and Ziller, 1959; Sampson, 1963).

Another student of congruence in small groups, Homans, has offered a conceptual framework within which congruence among dimensions of human relationships might be examined. Homans (1961) introduces the concept of distributive justice as a means of articulating the importance of congruence in the many dimensions of interpersonal relationships in small groups. The "rule of distributive justice" is stated thus:

A man in an exchange relation with another will expect that the rewards of each man be proportional to his costs--the greater the rewards, the greater the costs-and that the net rewards, or profits, of each man be proportional to his investments--the greater the investments, the greater the profit. (1961, p. 75)

Extending Homans' concept into the arena of problem solving processes, it would seem, hypothetically, that people would be less likely to be disturbed if the formal leader of a group made a decision for a group (hence received the greater reward), if he alone had invested his energies in gathering information which permitted a decision to be reached. And further, that individuals would become 
rather upset if, as group members, they had invested considerable energy in garnering information and other activities aimed at providing a basis for decision making, only to have the leader arbitrarily render a decision.

Following Homans' rationale, distributive justice in small group problem solving processes would exist when the participants' expenditures of energy' in the interaction structure were proportional to their expenditures of energy in the decision structure. The decision and interaction structures might then be described as congruent, i.e., participants who have a high investment of energy in the interaction system also have a proportionally high investment of energy in the decision system. Conversely, participants who have a low investment of energy in the interaction system also have a low investment of energy in the decision system.

To the extent that participants invest disproportionate energies in either the interaction or decision systems, there is a lack of structural congruence. Under the condition of structural incongruence participants who have a high investment of energies in the interaction system will have a disproportionately low investment of energies in the decision system. Conversely, participants who have a high investment of energies in the decision system will have a disproportionately low expenditure of energies in the interaction system. For example, a participant might find himself deeply involved in the interaction surrounding problem solving, but denied any part in the decision processes which lead to the problem solution. He might feel cheated. Similarly, a participant might find himself immersed in the 
decision process, without having participated substantially in the interaction necessary to arrive at the decision making stage of problem solution. Following Homans' rationale of economic exchange, this participant might feel as though he had "made a profit." However, an important by-product of the latter situation is that other participants must relinquish part of the group's collective decision making powers to this participant who has made little or no previous investment in the group's interaction processes. The condition of distributive justice is not present, and, following Homans, the resulting condition of social friction, including possible anger or resentment, will interfere with the current task.

In the present study it is proposed that problem solving groups be conceptualized as composed of interaction and decision structures, and that outcomes of the problem solving process be examined in relationship to the congruence of these structural variables. If this structural model were to be used as a conceptual tool in analyzing (or studying) problem solving groups, a number of theoretical problems might be more effectively dealt with.

1. Confusion and possible contraditions in the Shaw-MulderHutte research might be clarified, with the results of these studies being placed in the framework of outcomes of independent treatment of the structural dimensions of problem solving groups.

2. A step might be taken towards developing a more comprehensive, integrative model of group problem solving processes.

3. Such a model would provide for the systematic investigation of both the main effects and interaction of the structural; past research has not included such analyses. 
The Conceptual Model

Decision making or problem solving groups are conceptualized as composed of two structural sub-systems. These sub-systems are the interaction and decision structures. Each of these structural subsystems may vary in the degree of centrality which is present. Formally, definitions are as follows:

Interaction structure - the possible number of participating dyads in a group; i.e., the number of dyads in which communication may occur.

Centrality of interaction structure - the number of participating dyads divided by the maximum possible number of participating dyads.

Decision structure - the number of members whose consent (agreement) is required for a decision to be rendered by the group.

Centrality of decision structure - the number of participating decision makers divided by the maximum possible number of decision makers.

It should be noted that there must always be dyadic relationships between decision makers, although all possible dyadic relationships need not occur. In addition, there must always be at least one dyadic link between the decision structure and the interaction structure.

Finally, group structure can be described by the systematic properties of the interaction and decision structures. That is, the decision structure might be described as possessing the characteristic 
of high or low centrality. Similarly, the interaction structure might be described as possessing one of these systematic characteristics. To the extent that both interaction and decision structures are described in the same terms there is said to be structural congruence. To the extent that these structures are described by dissimilar terms, e.g., high decision centrality vs. low interaction centrality, there is said to be structural incongruence.

Figure 2 contains various combinations of high and low centrality of both intereaction and decision structures. Based on a 4 person group, intereaction and decision centrality are arbitrarily defined as follows:

$$
\begin{aligned}
\text { Interaction centrality (IC) - high } & =3 \text { dyads } \\
\text { low } & =6 \text { dyads } \\
\text { Decision centrality (DC) - high } & =1 \text { decision maker } \\
\text { low } & =4 \text { decision makers }
\end{aligned}
$$

\section{$\underline{\text { Structural Congruence }}$}

1. high

2. low

3. Low

4. high

\section{Centrality}

DC high

IC high

DC high

IC low

DC low

IC high

DC low

IC low $\underline{\text { Net }}$
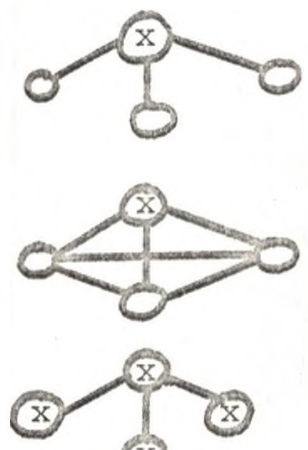

(x)

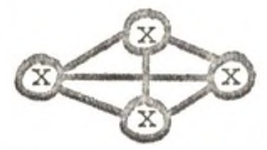

Fig. 2. Decision and interaction structures in 4 person groups. The circles represent positions, lines represent communication channels, and $x^{\prime}$ s represent decision maker positions. 
Hypotheses

The present research can be schematically represented as follows:

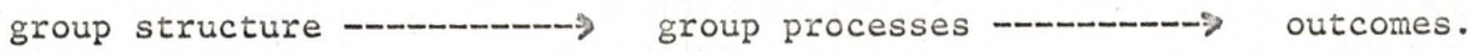
That is, varying interaction and decision centrality in group structure will lead to differences in group processes, e.g., opinion-information transmission regarding problem solution. These will lead to differences in group and individual outcomes, e.g., problem solutions and subjective satisfaction.

Hypothesis 1: Indices of centrality of group processes will reflect an interaction based on the congruence of the decision and interaction structures.

Hypothesis 2a: The problem solving effectiveness of the groups will reflect an interaction based on the congruence of the decision and interaction structures.

Hypothesis $2 \mathrm{~b}$ : The subjective satisfaction in the groups will reflect an interaction based on the congruence of the decision and interaction structures.

Within interaction structures of high or low centrality (see Figure 2), 1 or 4 positions might be designated in the decision structure. According to Mulder the fewer the number of persons contained in the decision structure the more likely the group is to be effective in its problem solving. Conversely, according to Hutte the greater the number of persons contained in the decision structure the more likely the group is to be effective in problem solving. The most effective problem solving groups, based on Mulder's research, would be Groups 1 and 2 in Figure 2. The most effective groups, based on 
Hutte's research, would be Groups 3 and 4. Predictions based on a theory of structural congruence would indicate that those groups which are structurally congruent will be most effective in their problem solutions; in this case, Groups 1 and 4.

Neither Mulder nor Hutte have concerned themselves with subjective satisfaction in problem solving groups. However, Shaw has found that groups with decentralized interaction structures tend to indicate greater satisfaction. Shaw has accounted for this via the concept of independence. However, Shaw's concept of independence, as developed earlier, is a one dimensional concept, relating to the interaction structure. Here, if used as a base for predictions, it must be extended to encompass both interaction and decision structures. Simpler, more parsimonious predictions can be based on the concept of structural congruence. 


\section{CHAPTER II}

\section{METHOD}

\section{Apparatus}

Following the general procedures of the early Bavelas and Leavitt research, Ss were seated in the groups so that each $\mathrm{S}$ was separated from those persons adjacent to him by a vertical partition from the table's center to its edge. The partitions contained slots which permitted Ss to transmit written messages wherever slots were open. Slots were selectively opened to construct wheel and all channel nets to represent the decision and interaction structures in Figure 2 (see above, p. 16). Each of the group positions was designated by a colored letter, visible to all group members, and Ss were supplied with message slips whose color matched those of the letter. Any message sent from a group position, or booth, was on a message slip. Decision maker positions in the groups were indicated by marking that booth with an $\mathrm{X}$ which was visible to all group members.

\section{Construction of Experimental Conditions}

The Ss, 96 male undergraduate volunteers from the University of North Dakota, were randomly assigned to both experimental conditions and positions within groups. The experimental conditions, with decision and interaction structures representing those indicated in Figure 2, were as follows: 
Condition 1. Decision centrality high, interaction centrality high: The person in position A was designated as the decision maker, and held the sole responsibility for rendering the final decision on the solution to the problem. The interaction was highly centralized, and focused on position A. Position A could communicate directly with any of the other position, however B, C, and D could communicate directly only with $A$. In order for $B, C$, or $D$ to communicate with each other the messages had to pass through A.

Condition 2. Decision centrality high, interaction centrality low: The person in position $\mathrm{A}$ was the decision maker, as in Condition 1, however communication took place in an all channel net. A person in any position could communicate directly with a person in any other position.

Condition 3. Decision centrality low, interaction centrality high: The groups were operating under consensus in their decision making; all members had to agree on a solution to the problem before a decision could be rendered. Communication was centralized, with only position A communicating directly with other positions. Positions $B, C$, and $D$ could communicate with each other only through position A.

Condition 4. Decision centrality low, interaction centrality low: The groups operated under consensus, as in Condition 3, and communication could flow directly between any position, as in Condition 2 .

Six groups $(n=6)$ were obtained for each of the 4 types of situations. 
The preceding is summarized as follows:

Interaction Centrality

\begin{tabular}{|c|c|c|c|}
\hline \multirow{3}{*}{$\begin{array}{l}\text { Decision } \\
\text { Centrality }\end{array}$} & \multirow[b]{2}{*}{ high } & high & low \\
\hline & & $\underset{n=6}{\operatorname{Ce} 11} 1$ & $\begin{array}{l}\text { Ce11 } \\
n=6\end{array}$ \\
\hline & low & $\begin{array}{l}\text { Cell } 3 \\
n=6\end{array}$ & $\begin{array}{l}\text { Ce11 } 4 \\
n=6\end{array}$ \\
\hline
\end{tabular}

Cells 1 and 4 were described as structurally congruent, and

Cells 2 and 3 as structurally incongruent.

The problems which the groups were required to solve were 3 complex problems designed by Shaw (1954b), and widely used in problem solving research (see Table 1). The problems were as follows:

Problem 1. A small company is moving from one office building to another. It must move four kinds of equipment: chairs, desks, filing cabinets, and typewriters. How many trucks are needed to make the move in one trip?

Items of information:

Each truck will carry 12 typewriters and nothing else.

The company owns a total of 15 filing cabinets.

The company owns a total of 12 typewriters.

Each truck will carry 5 filing cabinets and nothing else.

Each truck will carry 24 chairs and nothing else.

Each truck will carry 3 desks and nothing else.

The company owns a total of 48 chairs.

The company owns a total of 12 desks. Answer: 10 trucks.

Problem 2. A clothing dealer wanted to dispose of some of his winter clothing at the beginning of summer. He marked down the following items: coats, sweaters, trousers and shirts. What was the total amount of reduction?

Items of information:

Each coat was reduced from $\$ 30$ to $\$ 18$.

There were 22 coats altogether.

Each sweater was reduced from $\$ 20$ to $\$ 13$.

There were 5 sweaters altogether.

Each pair of trousers were reduced from $\$ 15$ to $\$ 12.50$.

There were 14 pairs of trousers altogether.

Each shirt was reduced from $\$ 10$ to $\$ 7.50$.

Altogether, there were 20 shirts.

Answer: $\$ 384$. 
Problem 3. Your group represents an electrical concern and you must decide how much to bid on a job of installing lighting equipment for a stadium. What will you bid?

Items of information:

The stadium must have 10 banks of lights.

Each bank of lights requires 20 light bulbs.

Each bank of lights requires 2 steel poles for support.

Light bulbs cost $\$ 1$ each.

Steel poles cost $\$ 50$ each.

10,000 feet of wire will be required.

The wire costs $\$ 5$ per 1,000 feet.

You want to make a profit of $\$ 1,000$. Answer: $\$ 2,250$.

Upon arrival in the experimental setting, Ss were randomly

assigned to experimental conditions and positions within groups. Then,

the following instructions were read:

Each of you are now members of a small group. The purpose of each group is to solve 3 problems which will be given to you.

You are sitting behind a panel which has slots open to other positions in the group. The purpose of these slots is to provide you with channels for written communication with the persons in your group. All communications are to be written. No talking will be permitted. Before you are note pads. These are for you to use in communicating with members of your group. Keep your messages simple. Try to communicate only one thing when you write a message. For each new communication use a new slip of paper. When passing on or adding to an old communication, make sure you endorse the message.

Notice that each position in each group is designed by the letter A, B, C, or D. Use these letters when sending messages.

The slots allow you to communicate in certain directions. Some of you can communicate with every member of your small group. Others of you can communicate with only one other member of your small group. In any case, you can communicate with only in the directions indicated by the slots. If you wish to communicate with someone where there is no slot, this must be done through the help of others in the group acting as relays for you.

Some positions are marked with an $\mathrm{X}$. An $\mathrm{X}$ indicates a decision maker. That is, the person or persons in positions marked with an $\mathrm{X}$ must make the final decision on the group's solution to the problem. In 2 groups, one person has this final decision to make. When he feels that the group has reached a solution which is satisfactory to him, he will inform the research 
assistant. In 2 groups this decision making is shared by all members of the group. They must all agree on the solution to the problem. In these groups the problem is not considered solved until all the groups' members agree on the solution.

The research assistants will now answer any questions you might have. Afterwards they will distribute the first problem. With the problem, they will give each of you some, but not a11, of the information needed to solve the problem. Your job is to work out ways of putting the information together and solving the problem.

You will be timed. Try to work efficiently, but do not try to work so rapidly that you destroy your group's problem solving effectiveness.

After the instructions had been read, each $\mathrm{E}$ answered questions from the Ss. Following this, Ss were asked if they were ready to begin. Each group member was then given three $5^{\prime \prime} \times 7 "$ note cards. On the first was the problem. On the second and third cards were single elements of information necessary in the solution of the problem. The total of information for each problem was randomly distributed among group members. When Ss had received the three information cards, E signaled them to begin reading the cards. At that time $\mathrm{E}$ began recording the group's time to solution.

When the group had completed the problem $E$ recorded the time to solution. E then collected the solution to the problem, and all messages transmitted during the problem solving process. Upon completion of the third problem the following $100 \mathrm{~mm}$ length rating scales were filled out by all ss: 
See if you can recall how you felt about your job on each problem. Place a check on each scale to indicate your feelings about your job on each problem.

Problem 1

\begin{tabular}{ccc}
\hline 0 & 50 & 100 \\
disliked & liked \\
it & & it
\end{tabular}

Problem 2

\begin{tabular}{ccc}
\hline 0 & 50 & 100 \\
disliked & liked \\
it & & it
\end{tabular}

Problem 3

\begin{tabular}{ccc}
\hline 0 & 50 & 100 \\
disliked & liked \\
it & & it
\end{tabular}

Place a check on the following scale to indicate your view of your group's overall problem solving effectiveness.

\begin{tabular}{crr}
\hline 0 & 50 & 100 \\
poor & good \\
inefficient & & efficient
\end{tabular}

Did your group have a leader? If so, who (which position, A, B, C, D)?

Upon completing the rating scales, Ss were dismissed from the experiment. 


\section{CHAPTER III}

RESULTS

\section{Treatment of the Data}

Because of negative skewness in the rating scale data, and positive skewness in the latency data, all data were subjected to a logarithmic transformation before being analyzed by an analysis of variance. The original data is presented in the Appendix. The data presented in the mean, and analysis of variance summary tables are logarithmic values.

The Congruence Model and Indices of Group Process

Hypothesis 1 predicted that indices of group process would reflect the congruence of the decision and interaction structures. The two indices employed in the present study were the number of information transactions and time to solution on each problem. Information transactions are defined as sums of the number of messages sent and received for each position, in each structural condition, on each problem. Table 2 presents the means and analysis of variance summary of the $10 \mathrm{~g}$ of the number of information transactions for each position in each of the 4 types of situations. Significant main effects were found across positions, and for the conditions of decision and interaction centrality. Significant interactions occurred between position by interaction centrality, and 
TABLE 2

NUMBER OF INFORMATION TRANSACTIONS TO SOLUTION, TYPE OF GROUP STRUCTURE BY POSITION (TRANSFORMED DATA)

\begin{tabular}{|c|c|c|c|c|c|c|c|c|c|c|}
\hline & & $\begin{array}{l}\text { DC high } \\
\text { IC high }\end{array}$ & $\begin{array}{l}\text { DC high } \\
\text { IC low }\end{array}$ & $\begin{array}{l}\text { DC low } \\
\text { IC high }\end{array}$ & $\begin{array}{l}\text { DC low } \\
\text { IC low }\end{array}$ & DC high & DC 1ow & IC high & IC low & Overa11 \\
\hline $\mathrm{N}$ & & 6 & 6 & 6 & 6 & 12 & 12 & 12 & 12 & 24 \\
\hline \multirow[t]{2}{*}{ Position A } & $\bar{x}$ & 1.974 & 1.996 & 2.365 & 2.146 & 1.985 & 2.255 & 2.169 & 2.071 & 2.120 \\
\hline & $\mathrm{S}$ & 0.313 & 0.146 & 0.207 & 0.182 & 0.233 & 0.218 & 0.325 & 0.176 & 0.260 \\
\hline \multirow[t]{2}{*}{ Position B } & $\overline{\mathrm{x}}$ & 1.456 & 1.855 & 1.940 & 2.112 & 1.655 & 2.026 & 1.698 & 1.983 & 1.841 \\
\hline & $\mathrm{s}$ & 0.409 & 0.188 & 0.192 & 0.151 & 0.369 & 0.187 & 0.396 & 0.211 & 0.343 \\
\hline \multirow[t]{2}{*}{ Position C } & $\bar{x}$ & 1.506 & 1.897 & 1.969 & 2.131 & 1.702 & 2.050 & 1.738 & 2.014 & 1.876 \\
\hline & $\mathrm{S}$ & 0.319 & 0.181 & 0.200 & 0.162 & 0.321 & 0.193 & 0.350 & 0.204 & 0.314 \\
\hline \multirow[t]{2}{*}{ Position D } & $\overline{\mathrm{x}}$ & 1.481 & 1.914 & 1.812 & 2.103 & 1.698 & 1.958 & 1.646 & 2.009 & 1.828 \\
\hline & $\mathbf{S}$ & 0.331 & 0.131 & 0.193 & 0.220 & 0.330 & 0.249 & 0.310 & 0.199 & 0.315 \\
\hline \multirow[t]{2}{*}{ Overa11 } & $\overline{\mathrm{x}}$ & 1.604 & 1.916 & 2.021 & 2.123 & 1.760 & 2.072 & 1.813 & 2.020 & 1.916 \\
\hline & $\mathbf{S}$ & 0.389 & 0.161 & 0.280 & 0.169 & 0.334 & 0.235 & 0.396 & 0.194 & 0.327 \\
\hline
\end{tabular}


TABLE 2--Continued

Summary of Analysis of Variance

\begin{tabular}{lcccc} 
Source of Variation & SS & df & MS & F \\
\hline Position (A) & 1.3625490 & 3 & 0.4541829 & $8.3582 * *$ \\
Decision Centrality (B) & 2.3422850 & 1 & 2.3422850 & $43.1045 * *$ \\
Interaction Centrality (C) & 1.0261230 & 1 & 1.0261230 & $18.8835 * *$ \\
A X B & 0.0551757 & 3 & 0.1839193 & 0.3384 \\
A X C & 0.7695313 & 3 & 0.2565104 & $4.7205 * *$ \\
B X C & 0.2636719 & 1 & 0.2636719 & $4.8529 *$ \\
A X B X C & 0.0100097 & 3 & 0.0033365 & 0.0614 \\
Error & 4.3471680 & 80 & 0.0543396 & \\
Total & 10.1765136 & 95 & & \\
\hline
\end{tabular}

$\begin{array}{rl}* p & <.05 \\ * * & p<.01\end{array}$

decision by interaction centrality. These are graphically illustrated in Figures 3 and 4 , respectively.

Note in Figure 3 that position $A$ has the highest mean number of information transactions in all conditions except that of low decision and low interaction centrality. This reflects the key role played by position $\mathrm{A}$ in either the decision or interaction structures, or both, under all but the latter condition. No appreciable differences occurred between the other positions. The interaction of position by interaction centrality reflects the communication demands placed on position A under the condition of high interaction centrality; that is, all communication had to pass to or through position A. 


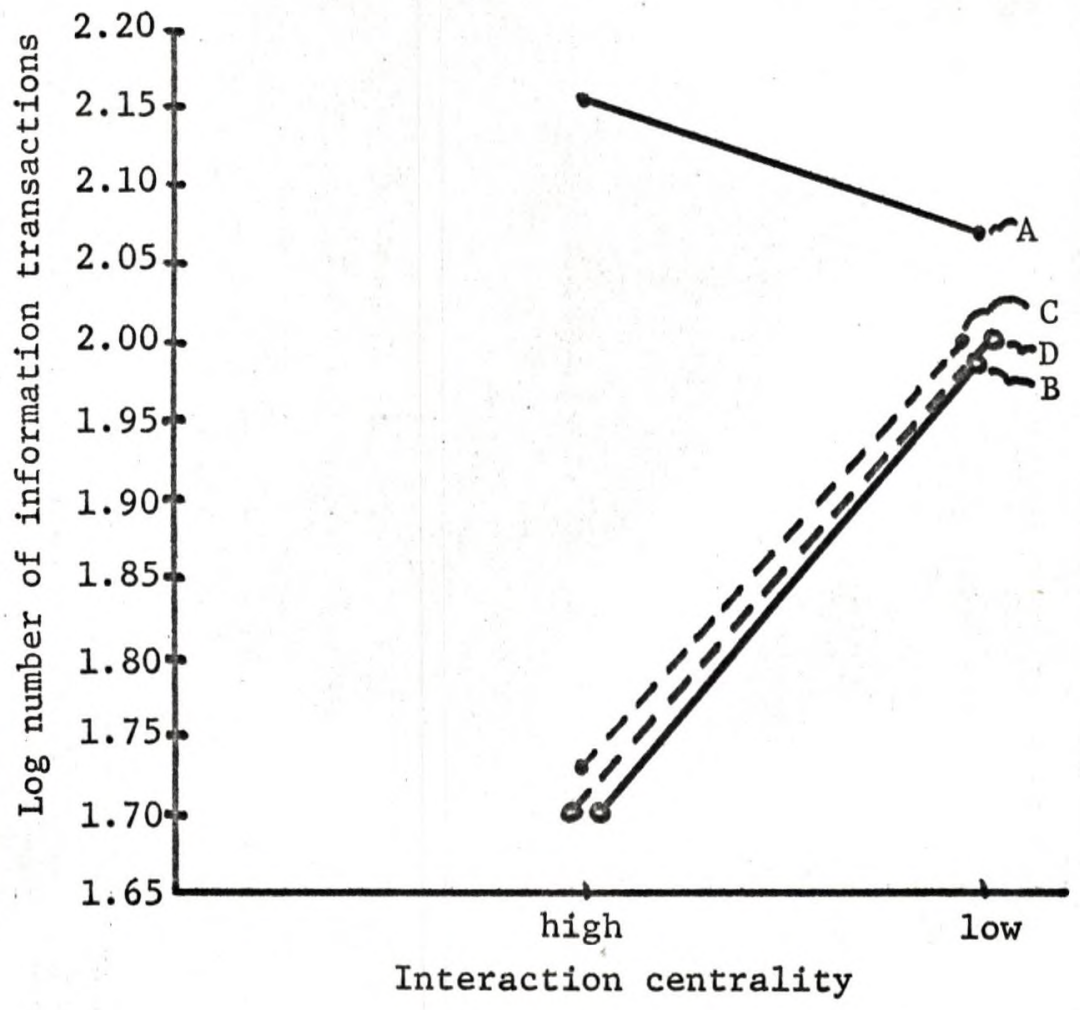

Fig. 3. Log of the number of information transactions for the interaction of group position and the conditions of interaction centrality. 


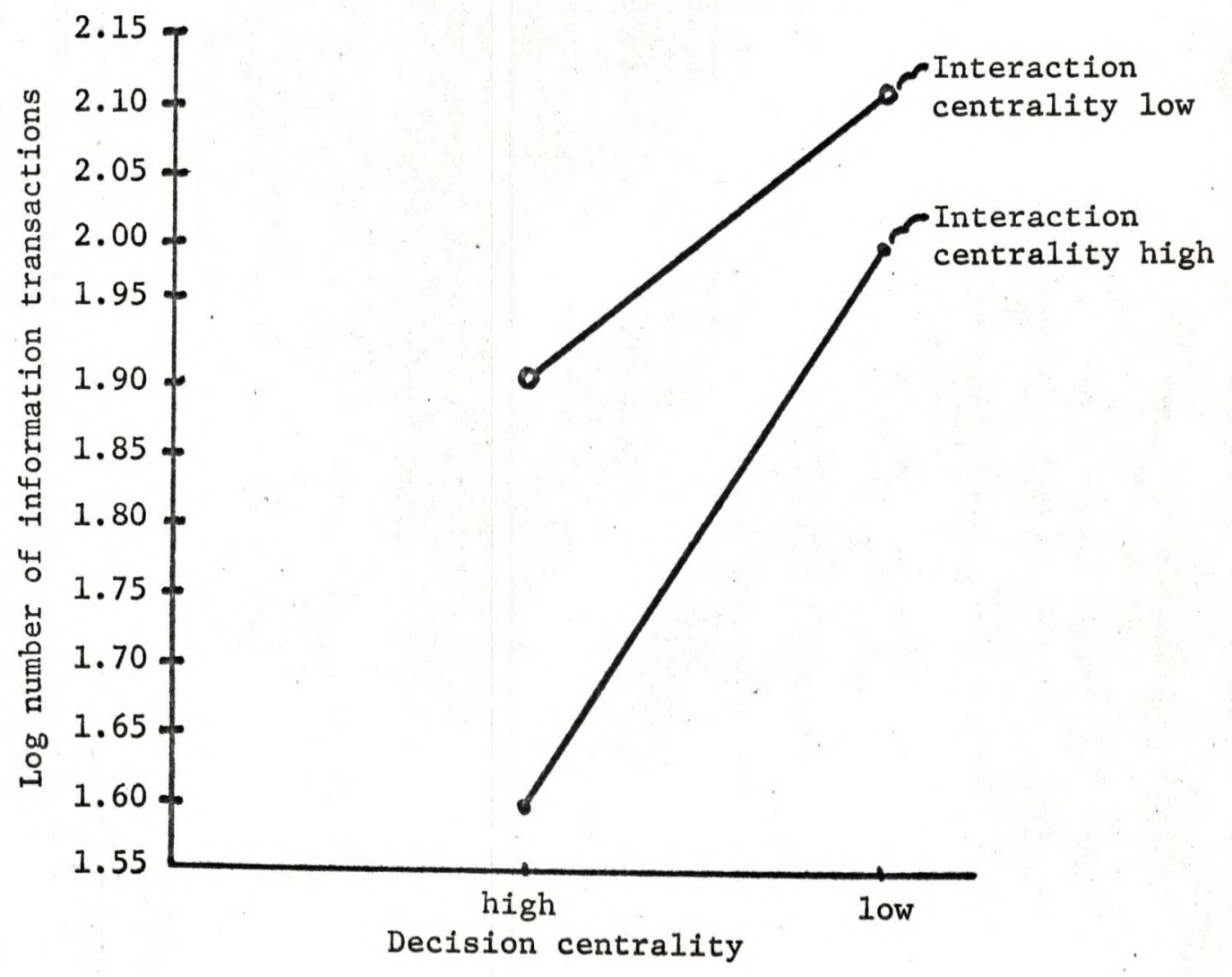

Fig. 4. Log of the number of information transactions for the interaction of decision and interaction centrality. 
Table 3 summarizes findings regarding the number of information transactions to solution of each problem for the 4 types of groups. Significant, or near significant, main effects were found for the conditions of high or low decision and interaction centrality across the 3 problems. That is, the number of information transactions decreased from problem 1 through problem 3; was lower under the condition of high decision centrality; and was lower under the condition of high interaction centrality. Problem 1 required significantly fewer information transactions than problems 2 or $3, \mathrm{p}<.05$.

However, Table 3 also indicates an interaction between the conditions of decision and interaction centrality. This is graphically presented in Figure 5. It indicates that predictions regarding the number of information transactions necessary to reach problem solution should be made with consideration given to the structural congruence of the decision and interaction structures. This finding provides support for Hypothesis 1.

In Figure 6 some characteristics of structurally congruent and incongruent groups become apparent. When the dimensions of decision and interaction centrality are both high or low, described as structurally congruent groups, there occurred a progressive decrease in the number of information transactions necessary to reach problem solution. The preceding was not true for groups operating with incongruent decision and interaction structures. The ordinal relationships for frequency of information transactions on problems 2 and 3 were different from those found with structurally congruent models. 
TABLE 3

NUMBER OF INFORMATION TRANSACTIONS TO SOLUTION, TYPE OF GROUP STRUCTURE BY PROBLEM (TRANSFORMED DATA)

\begin{tabular}{|c|c|c|c|c|c|c|c|c|c|c|}
\hline & & $\begin{array}{l}\text { DC high } \\
\text { IC high }\end{array}$ & $\begin{array}{l}\text { DC high } \\
\text { IC low }\end{array}$ & $\begin{array}{l}\text { DC low } \\
\text { IC high }\end{array}$ & $\begin{array}{l}\text { DC 1ow } \\
\text { IC 1ow }\end{array}$ & DC high & DC 1ow & IC high & IC low & Overall \\
\hline $\mathrm{N}$ & & 6 & 6 & 6 & 6 & 12 & 12 & 12 & 12 & 24 \\
\hline \multirow[t]{2}{*}{ Problem 1} & $\bar{x}$ & 1.857 & 2.087 & 2.328 & 2.367 & 1.972 & 2.348 & 2.093 & 2.227 & 2.160 \\
\hline & $\mathrm{S}$ & 0.166 & 0.175 & 0.171 & 0.105 & 0.202 & 0.137 & 0.294 & 0.201 & 0.256 \\
\hline \multirow[t]{2}{*}{ Problem 2} & $\overline{\mathrm{X}}$ & 1.755 & 1.992 & 2.096 & 2.162 & 1.873 & 2.120 & 1.926 & 2.077 & 2.001 \\
\hline & $\mathrm{s}$ & 0.498 & 0.198 & 0.169 & 0.233 & 0.382 & 0.197 & 0.397 & 0.224 & 0.325 \\
\hline \multirow[t]{2}{*}{ Problem 3} & $\bar{x}$ & 1.678 & 2.012 & 2.165 & 2.156 & 1.845 & 2.161 & 1.922 & 2.084 & 2.003 \\
\hline & $\mathrm{S}$ & 0.382 & 0.183 & 0.257 & 0.254 & 0.335 & 0.243 & 0.401 & 0.224 & 0.328 \\
\hline \multirow[t]{2}{*}{ Overa11 } & $\bar{x}$ & 1.763 & 2.030 & 2.197 & 2.229 & 1.897 & 2.213 & 1.980 & 2.129 & 2.005 \\
\hline & $\mathrm{S}$ & 0.360 & 0.179 & 0.215 & 0.220 & 0.311 & 0.215 & 0.366 & 0.222 & 0.310 \\
\hline
\end{tabular}


TABLE 3--Continued

\begin{tabular}{lccccc}
\hline & Summary of Analysis of Variance & MS & F \\
Source of Variation & SS & df & F \\
\hline Problem (A) & 0.3977051 & 2 & 0.1988525 & $3.0690+$ \\
Decision Centrality (B) & 1.7961430 & 1 & 1.7961430 & $27.7256 * *$ \\
Interaction Centrality (C) & 0.4016113 & 1 & 0.4016113 & $6.1993 *$ \\
A X B & 0.0429687 & 2 & 0.0214843 & 0.3316 \\
A X C & 0.0024414 & 2 & 0.0012207 & 0.0188 \\
B X C & 0.2478027 & 1 & 0.2478027 & $3.8251+$ \\
A X B X C & 0.0263671 & 2 & 0.0131835 & 0.2035 \\
Error & 3.8869630 & 60 & 0.0647826 & \\
Total & 6.8020023 & 71 & & \\
\hline
\end{tabular}

$+p<.10$
$* p<.05$
$* * p<.01$

Table 4 presents means and summary of analysis of variance for the log of time to solution, in seconds, for each type group across the 3 problems. Significant main effects are indicated across problems, and under the conditions of decision centrality. A near significant interaction occurs between the conditions of decision and interaction centrality. Thus, time to solution cannot be predicted on the basis of knowledge of the decision structure alone. These findings are indicated in Figure 7.

Mulder's findings of virtually the same time to solution for centralized or decentralized interaction nets when a centralized 


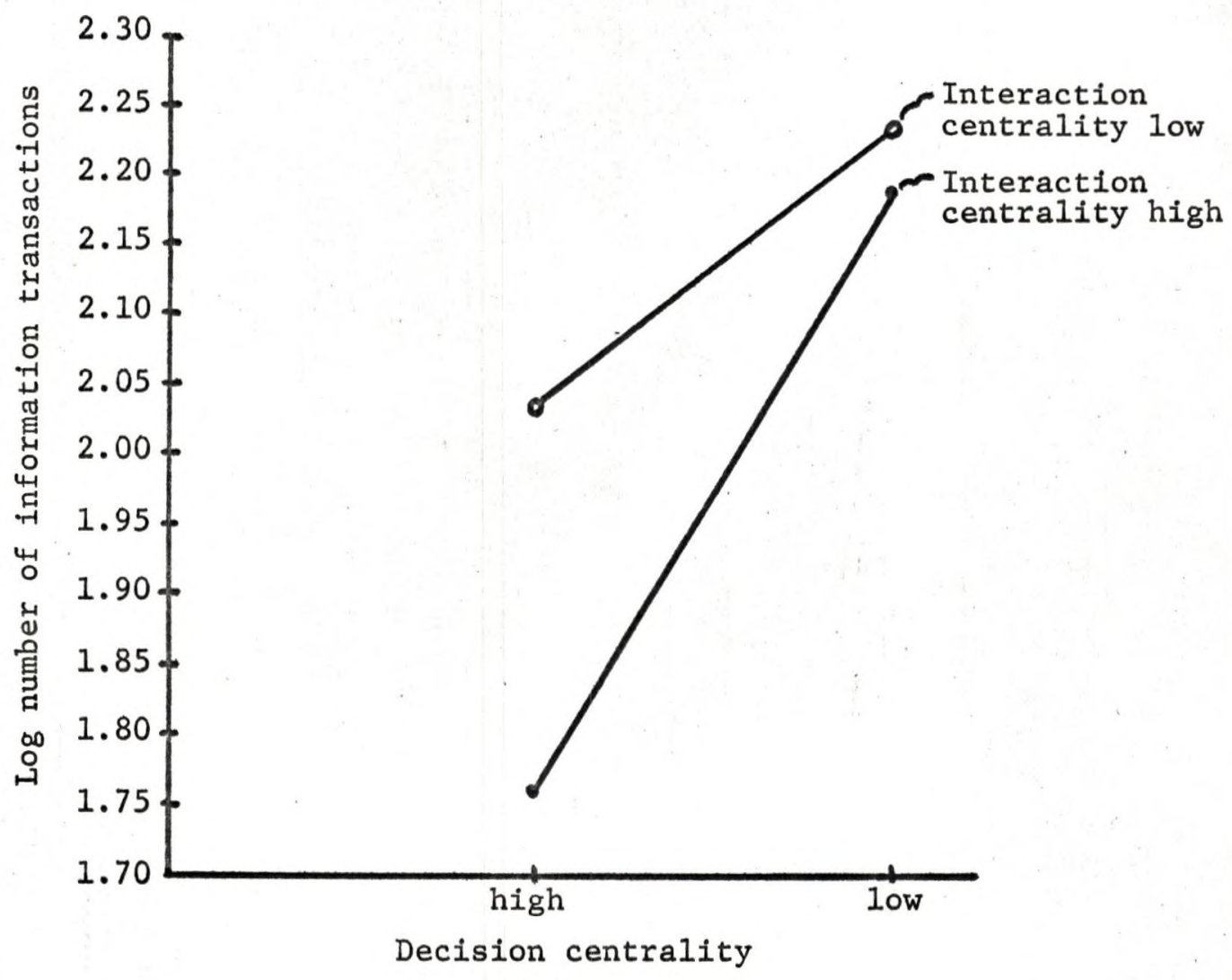

Fig. 5. Log of the number of information transactions to solution for the interaction of the conditions of group structure across problems. 


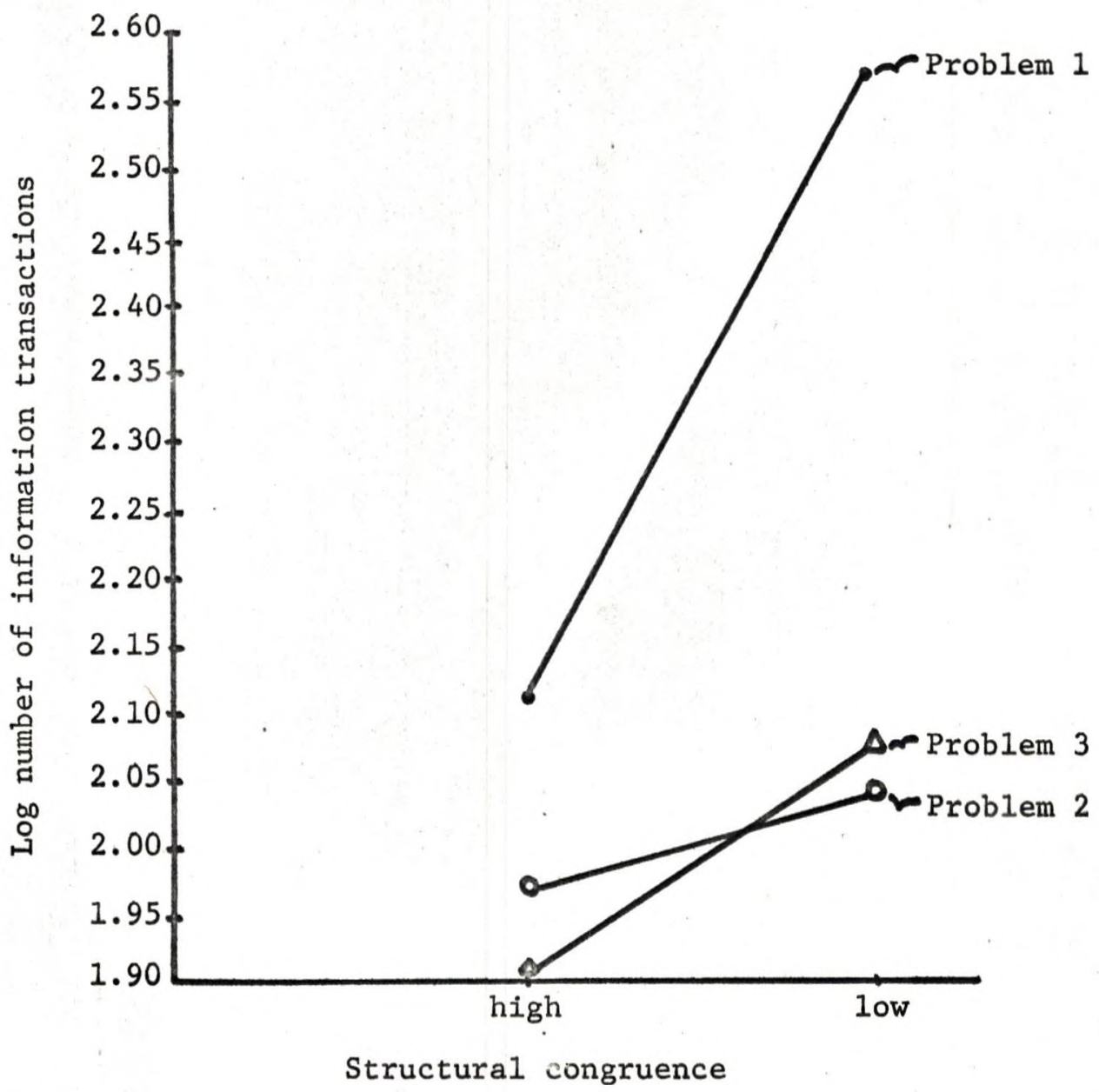

Fig. 6. Log of number of information transactions to solution for each problem under the conditions of structural congruence. 
TABLE 4

SOLUTION TIME, TYPE OF GROUP STRUCTURE BY PROBLEM (TRANSFORMED DATA)

\begin{tabular}{|c|c|c|c|c|c|c|c|c|c|c|}
\hline & & $\begin{array}{l}\text { DC high } \\
\text { IC high }\end{array}$ & $\begin{array}{l}\text { DC high } \\
\text { IC low }\end{array}$ & $\begin{array}{l}\text { DC low } \\
\text { IC high }\end{array}$ & $\begin{array}{l}\text { DC low } \\
\text { IC low }\end{array}$ & DC high & DC low & IC high & IC 1ow & Overall \\
\hline $\mathrm{N}$ & & 6 & 6 & 6 & 6 & 12 & 12 & 12 & 12 & 24 \\
\hline \multirow[t]{2}{*}{ Problem 1} & $\bar{x}$ & 2.802 & 2.927 & 3.195 & 3.101 & 2.864 & 3.148 & 2.998 & 3.014 & 3.006 \\
\hline & $\mathrm{S}$ & 0.128 & 0.244 & 0.157 & 0.135 & 0.197 & 0.148 & 0.247 & 0.209 & 0.224 \\
\hline \multirow[t]{2}{*}{ Problem 2} & $\overline{\mathrm{X}}$ & 2.658 & 2.689 & 3.000 & 2.897 & 2.674 & 2.949 & 2.829 & 2.793 & 2.811 \\
\hline & $\mathrm{s}$ & 0.336 & 0.228 & 0.194 & 0.212 & 0.274 & 0.201 & 0.316 & 0.236 & 0.274 \\
\hline \multirow[t]{2}{*}{ Problem 3} & $\bar{x}$ & 2.596 & 2.679 & 2.959 & 2.847 & 2.637 & 2.903 & 2.778 & 2.763 & 2.770 \\
\hline & $\mathrm{s}$ & 0.212 & 0.186 & 0.272 & 0.281 & 0.195 & 0.270 & 0.300 & 0.243 & 0.267 \\
\hline \multirow[t]{2}{*}{ Overa11 } & $\overline{\mathrm{x}}$ & 2.685 & 2.765 & 3.051 & 2.948 & 2.725 & 3.000 & 2.868 & 2.857 & 2.862 \\
\hline & $\mathrm{s}$ & 0.243 & 0.239 & 0.226 & 0.233 & 0.241 & 0.233 & 0.297 & 0.251 & 0.273 \\
\hline
\end{tabular}


TABLE 4--Continued

$\begin{array}{ccc} & \text { Summary of Analysis of Variance } \\ \text { Source of Variation } & \text { SS df MS }\end{array}$

\begin{tabular}{lcccc}
\hline Problem (A) & 0.7624512 & 2 & 0.3812256 & $7.6594 * *$ \\
Decision Centrality (B) & 1.3601070 & 1 & 1.3601070 & $27.32668 * *$ \\
Interaction Centrality (C) & 0.0024414 & 1 & 0.0024414 & 0.0490 \\
A X B & 0.0007324 & 2 & 0.0003662 & 0.0073 \\
A X C & 0.0075683 & 2 & 0.0037841 & 0.0760 \\
B X C & 0.1503906 & 1 & 0.1503906 & $3.0215+$ \\
A X B X C & 0.0058593 & 2 & 0.0029296 & 0.0588 \\
Error & 2.9863280 & 60 & 0.0497721 & \\
Total & 5.2758782 & 71 & & \\
\hline
\end{tabular}

$+\mathrm{p}<.10$

$* * \mathrm{p}<.01$

decision structure was present in both nets, did not occur here. Rather, the conditions of interaction under which a centralized or decentralized decision structure operated were of considerable importance, leading to the interaction between the conditions of decision and interaction centrality. Thus, within the conditions of structurally congruent or incongruent decision and interaction systems, structurally congruent groups took less time than structurally incongruent groups. This finding lends support to Hypothesis 1 .

As a further means of validating the existence and functioning of centralized or decentralized decision structures, Ss were asked for leader nominations. Table 5 indicates the number of leader nominations 


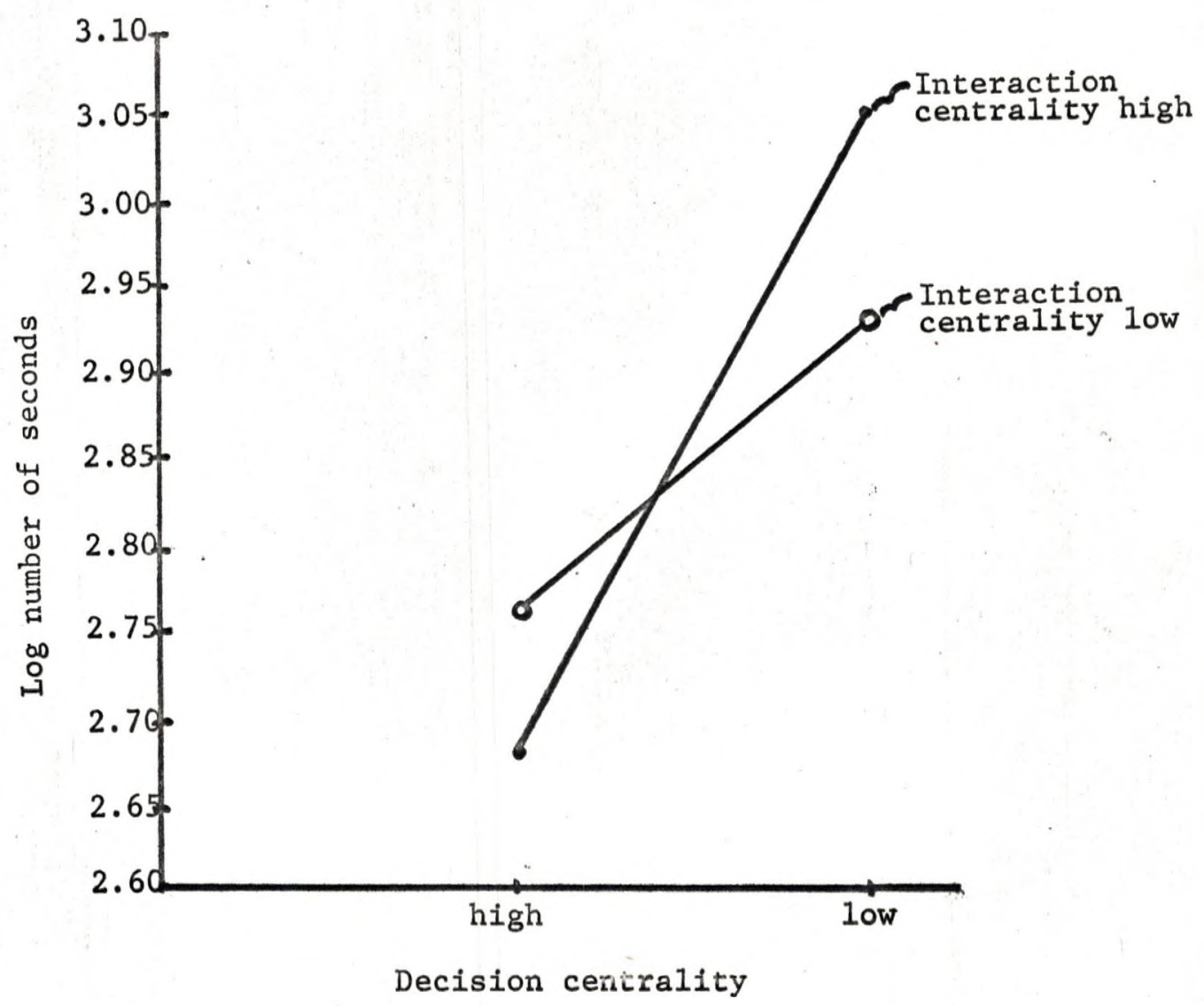

Fig. 7. Log number of seconds to solution for the interaction of the conditions of group structure. 
for each position under the conditions of high and low decision centrality. Observed column totals differ because of some Ss nominating more than one leader. The data indicate that leadership was perceived to be more focalized, or concentrated in a limited number of positions, under the condition of high, rather than low, decision centrality. This finding serves to validate the hypothesized establishment of centralized or decentralized decision structures.

\section{TABLE 5}

LEADER NOMINATIONS UNDER CONDITIONS OF HIGH AND LOW DECISION CENTRALITY

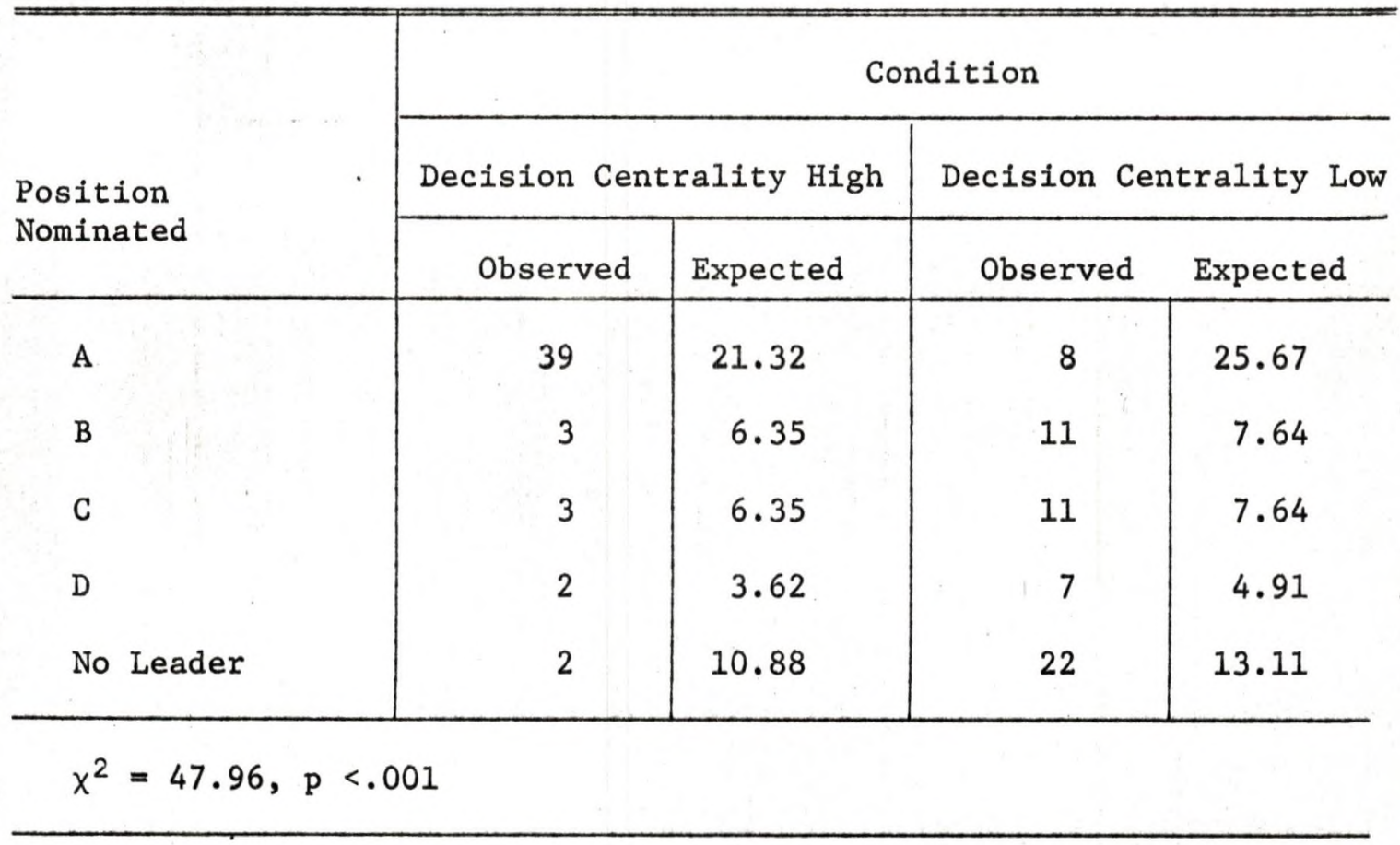

The Congruence Model and Outcomes

Hypothesis 2 a predicted that the greater the congruence between the decision and interaction structures, the greater would be the problem solving effectiveness of the group. 
Each group's solution to each problem was categorized as right or wrong. These dichotomous data were analyzed with Cochran's Q. A frequency sumary is indicated in Table 6. The significant Cochran's Q (DC high < DC low) indicates that a decentralized decision structure was significantly more accurate than a centralized decision structure. The centrality of the interaction structure had virtually no effect on accuracy of problem solving. These data do not lend support to Hypothesis 2a. Neither do these data support models of problem solving advanced by Mulder or Shaw et al. (see Figure 1).

TABLE 6

ACCURACY OF SOLUTIONS TO PROBLEMS $1-3$

\begin{tabular}{|c|c|c|c|c|c|c|}
\hline & & Right & Wrong & Right & Wrong & $\sum$ Right \\
\hline \multirow{3}{*}{ Decision Centrality } & high & 8 & 10 & 10 & 8 & $18 *$ \\
\hline & low & 15 & 3 & 15 & 3 & 30 \\
\hline & $\sum$ right & \multicolumn{2}{|c|}{$\begin{array}{l}23 * * \\
\text { high }\end{array}$} & \multicolumn{2}{|c|}{${ }^{25}$ low } & \\
\hline
\end{tabular}

Interaction Centrality

*Cochran's Q, DC high vs DC low $=9.00, \mathrm{p}<.01$

$* *$ Cochran's Q, IC high vs IC low $=0.28, \mathrm{p}<.70$

Table 7 indicates summaries of means and analysis of variance of $\log$ rated effectiveness of problem solving in each type group. A significant main effect was found for the condition of decision centrality. Ss in groups constructed with centralized decision structures rated their groups as significantly more effective in problem 
TABLE 7

RATED EFFECTIVENESS OF PROBLEM SOLVING, BY TYPE OF GROUP STRUCTURE (TRANSFORMED DATA)

\begin{tabular}{llllllllll}
\hline \hline $\begin{array}{l}\text { DC high } \\
\text { IC high }\end{array}$ & $\begin{array}{l}\text { DC high } \\
\text { IC low }\end{array}$ & $\begin{array}{l}\text { DC low } \\
\text { IC high }\end{array}$ & $\begin{array}{l}\text { DC low } \\
\text { IC low }\end{array}$ & DC high & DC 1ow & IC high & IC low & Overall \\
\hline $\mathrm{N}$ & 6 & 6 & 6 & 6 & 12 & 12 & 12 & 12 & 24 \\
$\overline{\mathrm{X}}$ & 1.85 & 1.81 & 1.69 & 1.71 & 1.83 & 1.70 & 1.77 & 1.76 & 1.76 \\
$\mathrm{~S}$ & 0.09 & 0.10 & 0.16 & 0.20 & -.09 & 0.17 & 0.15 & 0.16 & -0.14 \\
\hline
\end{tabular}

Summary of Analysis of Variance

\begin{tabular}{lcccc}
\hline Source of Variation & SS & df & MS & F \\
\hline Decision Centrality (A) & 0.0970154 & 1 & 0.09740154 & $4.6093 * *$ \\
Interaction Centrality (B) & 0.0002747 & 1 & 0.0002747 & 0.0130 \\
A X B & 0.0050812 & 1 & 0.0050812 & 0.2414 \\
Within & 0.4209595 & 20 & 0.0210480 & \\
Total & 0.5233307 & & & \\
\hline
\end{tabular}

** $\mathrm{p}<.05$ 
solving than Ss in groups with decentralized decision structures. It should be noted that this finding contrasts with that concerning problem solving accuracy (see Table 6), which indicated that groups with decentralized decision structures were significantly more accurate than groups with centralized decision structures. These findings are contrasted in Figure 8 .

Table 8 summarizes the means and analysis of variance of $10 \mathrm{~g}$ rated effectiveness of problem solving for each position in each type group. While a significant main effect is indicated for the conditions of decision centrality, an interaction between position in each group and the condition of decision centrality approaches significance. This would indicate that the unique configurations of these factors should be taken into account before interpreting these data. An internal inspection of the data indicated that most of the variance leading to the position by decision centrality interaction occurred under the condition in which decision centrality was low and interaction centrality was high. Further, within this condition, position $D$, and to a lesser extent position C, accounted for most of the variance. This can be noted in Figure 9.

Overall, the data in Table 8 do not lend support to Hypothesis 2a. A decentralized decision structure, whether operating under the contingencies of a centralized or decentralized interaction structure, was perceived as more effective in its problem solving than a centralized decision structure.

Hypothesis $2 \mathrm{~b}$ predicted that subjective satisfaction would be greater in structurally congruent rather than structurally incongruent groups. 


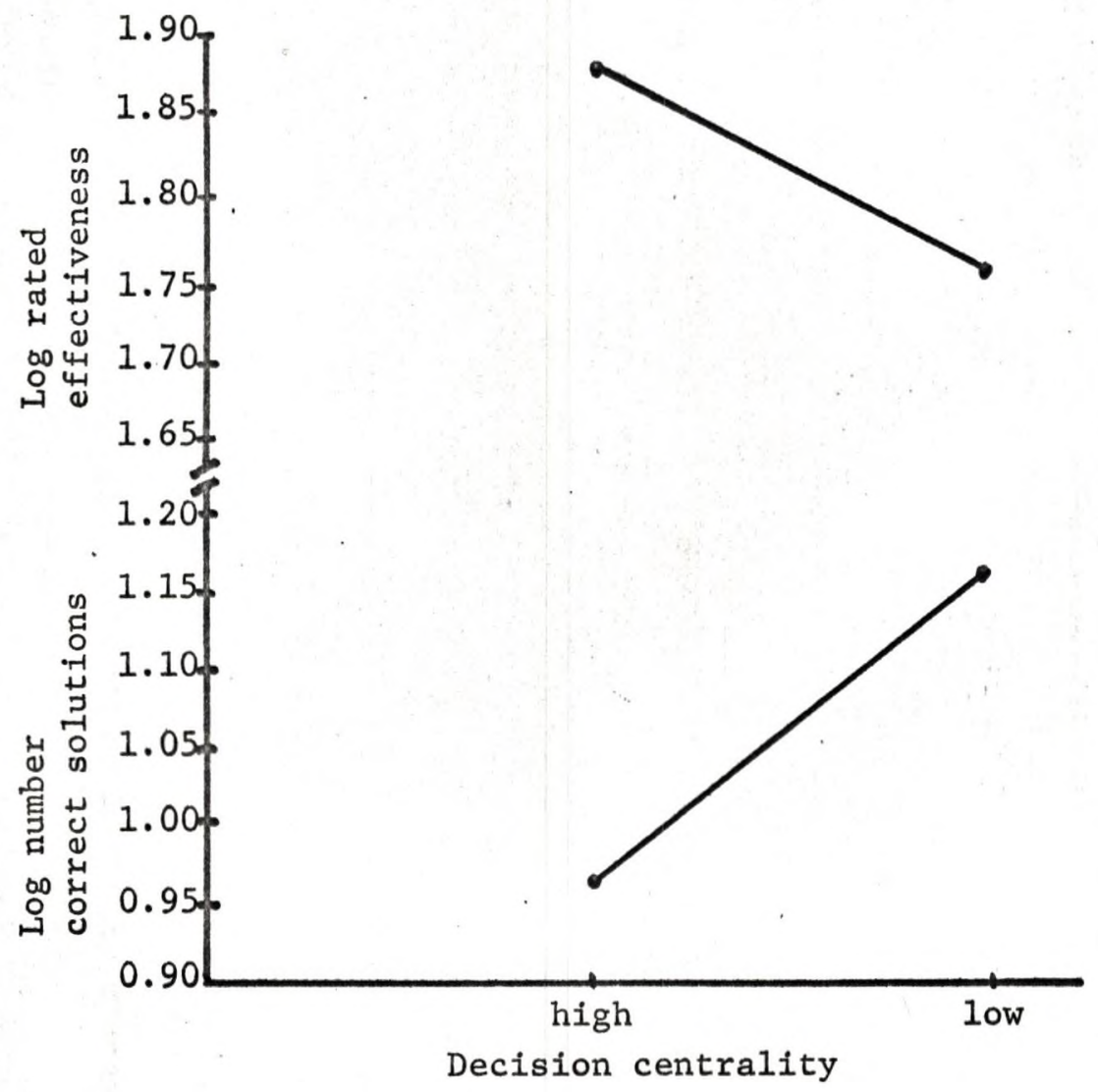

Fig. 8. Contrast of rated effectiveness and number of correct solutions under conditions of decision centrality. 
TABLE 8

RATED EFFECTIVENESS OF PROBLEM SOLVING, TYPE OF GROUP STRUCTURE BY POSITION (TRANSFORMED DATA)

\begin{tabular}{|c|c|c|c|c|c|c|c|c|c|c|}
\hline & & $\begin{array}{l}\text { DC high } \\
\text { IC high }\end{array}$ & $\begin{array}{l}\text { DC high } \\
\text { IC low }\end{array}$ & $\begin{array}{l}\text { DC low } \\
\text { IC high }\end{array}$ & $\begin{array}{l}\text { DC low } \\
\text { IC 1ow }\end{array}$ & DC high & DC low & IC high & IC 1ow & Overa11 \\
\hline $\mathrm{N}$ & & 6 & 6 & 6 & 6 & 12 & 12 & 12 & 12 & 24 \\
\hline \multirow[t]{2}{*}{ Position A } & $\bar{x}$ & 1.835 & 1.806 & 1.568 & 1.858 & 1.820 & 1.713 & 1.702 & 1.832 & 1.767 \\
\hline & $\mathrm{S}$ & 0.141 & 0.137 & 0.449 & 0.110 & 0.134 & 0.346 & 0.347 & 0.121 & 0.263 \\
\hline \multirow[t]{2}{*}{ Position B } & $\overline{\mathrm{X}}$ & 1.870 & 1.810 & 1.706 & 1.582 & 1.840 & 1.644 & 1.788 & 1.696 & 1.742 \\
\hline & $\mathrm{S}$ & 0.100 & 0.098 & 0.234 & 0.545 & 0.100 & 0.405 & 0.191 & 0.392 & 0.305 \\
\hline \multirow[t]{2}{*}{ Position C } & $\overline{\mathrm{x}}$ & 1.515 & 1.538 & 1.769 & 1.525 & 1.526 & 1.647 & 1.642 & 1.531 & 1.587 \\
\hline & $\mathrm{S}$ & 0.643 & 0.495 & 0.211 & 0.750 & 0.547 & 0.541 & 0.475 & 0.606 & 0.535 \\
\hline \multirow[t]{2}{*}{ Position D } & $\overline{\mathrm{x}}$ & 1.893 & 1.925 & 1.147 & 1.544 & 1.909 & 1.346 & 1.520 & 1.735 & 1.627 \\
\hline & $\mathrm{s}$ & 0.110 & 0.061 & 0.810 & 0.511 & 0.086 & 0.678 & 0.675 & 0.400 & 0.553 \\
\hline \multirow[t]{2}{*}{ Overa11 } & $\overline{\mathrm{X}}$ & 1.778 & 1.770 & 1.548 & 1.627 & 1.774 & 1.587 & 1.663 & 1.698 & 1.681 \\
\hline & s & 0.352 & 0.285 & 0.519 & 0.515 & 0.317 & 0.513 & 0.454 & 0.418 & 0.434 \\
\hline
\end{tabular}


TABLE 8--Continued

\begin{tabular}{lcccc}
\hline & Summary of Analysis of Variance & \\
Source of Variation & SS & df & MS & F \\
\hline Position (A) & 0.5495605 & 3 & 0.1831868 & 1.0390 \\
Decision Centrality (B) & 0.8356934 & 1 & 0.8356934 & $4.7401 *$ \\
Interaction Centrality (C) & 0.0305175 & 1 & 0.0305175 & 0.1731 \\
A X B & 1.4550780 & 3 & 0.4850260 & $2.7511+$ \\
A X C & 0.4719238 & 3 & 0.1573079 & 0.8922 \\
B X C & 0.0466308 & 1 & 0.0466308 & 0.2645 \\
A X B X C & 0.4196777 & 3 & 0.1398926 & 0.7934 \\
Error & 14.1042500 & 80 & 0.1763031 & \\
Total & 17.9133317 & 95 & & \\
\hline
\end{tabular}

$+p<.06$

$* \mathrm{p}<.05$

Subjective satisfaction was measured by the like-dislike reactions for Ss on each of the 3 problems. Table 9 presents a summary of means and analysis of variance for log rated satisfaction across the 3 problems. The conditions of interaction centrality lead to a near significant main effect, with decentralized interaction structures more satisfying than centralized interaction structures. Earlier research, e.g., Bavelas and Leavitt, had focused largely on simple centralized-decentralized interaction net comparisons, e.g., circle compared to wheel nets, and has indicated that spread interaction nets were more satisfying than centralized interaction nets. The present findings are consistent with past research. These data do not support a congruence model. 


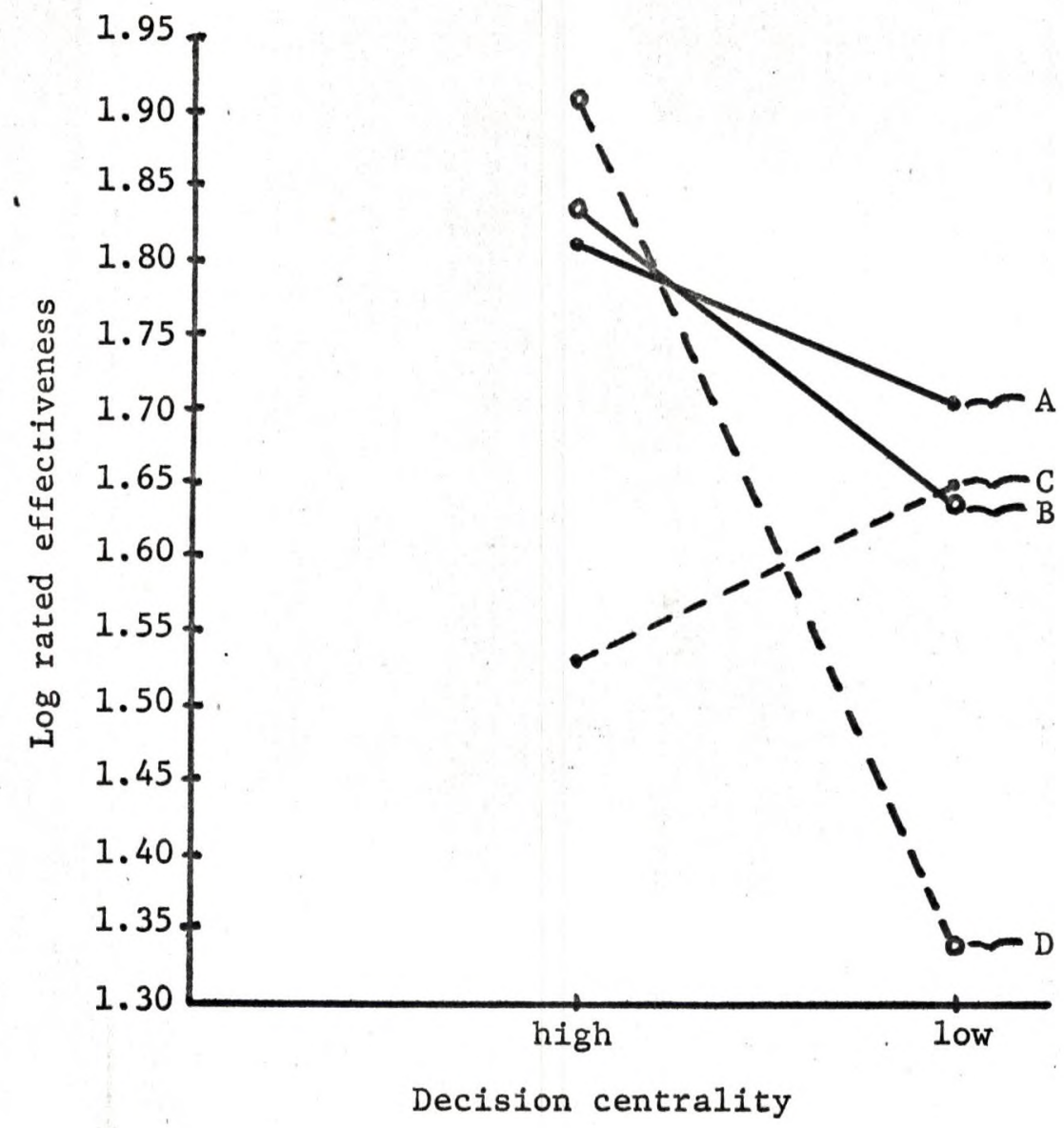

Fig. 9. Log of rated problem solving effectiveness for interaction of position and decision centrality. 
TABLE 9

RATED SATISFACTION, TYPE OF GROUP STRUCTURE BY PROBLEM (TRANSFORMED DATA)

\begin{tabular}{|c|c|c|c|c|c|c|c|c|c|c|}
\hline & & $\begin{array}{l}\text { DC high } \\
\text { IC high }\end{array}$ & $\begin{array}{l}\text { DC high } \\
\text { IC low }\end{array}$ & $\begin{array}{l}\text { DC low } \\
\text { IC high }\end{array}$ & $\begin{array}{l}\text { DC low } \\
\text { IC low }\end{array}$ & DC high & DC 1ow & IC high & IC low & Overal1 \\
\hline $\mathrm{N}$ & & 6 & 6 & 6 & 6 & 12 & 12 & 12 & 12 & 24 \\
\hline \multirow[t]{2}{*}{ Problem 1} & $\overline{\mathrm{x}}$ & 1.703 & 1.775 & 1.684 & 1.830 & 1.739 & 1.757 & 1.694 & 1.803 & 1.748 \\
\hline & $\mathrm{s}$ & 0.110 & 0.124 & 0.204 & 0.088 & 0.118 & 0.168 & 0.156 & 0.107 & 0.142 \\
\hline \multirow[t]{2}{*}{ Problem 2} & $\overline{\mathrm{x}}$ & 1.780 & 1.866 & 1.802 & 1.856 & 1.823 & 1.829 & 1.791 & 1.861 & 1.826 \\
\hline & $\mathrm{s}$ & 0.097 & 0.099 & 0.106 & 0.095 & 0.104 & 0.100 & 0.098 & 0.093 & 0.100 \\
\hline \multirow[t]{2}{*}{ Problem 3} & $\overline{\mathrm{x}}$ & 1.789 & 1.785 & 1.733 & 1.774 & 1.787 & 1.754 & 1.761 & 1.780 & 1.770 \\
\hline & $\mathbf{S}$ & 0.221 & 0.216 & 0.127 & 0.143 & 0.208 & 0.131 & 0.174 & 0.175 & 0.171 \\
\hline \multirow[t]{2}{*}{ Overa11 } & $\overline{\mathrm{X}}$ & 1.757 & 1.809 & 1.740 & 1.820 & 1.783 & 1.780 & 1.748 & 1.814 & 1.781 \\
\hline & $\mathrm{s}$ & 0.149 & 0.151 & 0.151 & 0.110 & 0.150 & 0.137 & 0.148 & 0.131 & 0.143 \\
\hline
\end{tabular}


TABLE 9--Continued

\begin{tabular}{lcccc}
\hline & \multicolumn{4}{c}{ Summary } \\
Source of Variation & SS & df & MS & F \\
\hline Problem (A) & 0.0771637 & 2 & 0.0385818 & 1.8626 \\
Decision Centrality (B) & 0.0001831 & 1 & 0.0001831 & 0.0088 \\
Interaction Centrality (C) & 0.0780944 & 1 & 0.00780944 & $3.7701+$ \\
A X B & 0.0084991 & 2 & 0.0042495 & 0.2051 \\
A X C & 0.0246124 & 2 & 0.0123062 & 0.5941 \\
B X C & 0.0037384 & 1 & 0.0037384 & 0.1804 \\
A X B X C & 0.0094757 & 2 & 0.0047378 & 0.2287 \\
Error & 1.2428280 & 60 & 0.0207138 & \\
Total & 1.4445948 & 71 & & \\
\hline + p <.10 & & & & \\
\hline
\end{tabular}

Table 10 summarizes an analysis of variance on log like-dislike reactions across positions in each type group. There are no significant findings. These data do not lend support to Hypothesis $2 \mathrm{~b}$.

Overall these findings yielded mixed support for a congruence model of small group problem solving. Indices of group process indicate that structural congruence is an important consideration. However, the outcomes of accuracy, perceived effectiveness, and satisfaction indicate that attention should be given to the conditions of the decision and interaction structures respectively. Whether these structures were congruent was not of critical importance. 
TABLE 10

RATED SATISFACTION, TYPE OF GROUP STRUCTURE BY POSITION (TRANSFORMED DATA)

\begin{tabular}{|c|c|c|c|c|c|c|c|c|c|c|}
\hline & & $\begin{array}{l}\text { DC high } \\
\text { IC high }\end{array}$ & $\begin{array}{l}\text { DC high } \\
\text { IC low }\end{array}$ & $\begin{array}{l}\text { DC low } \\
\text { IC high }\end{array}$ & $\begin{array}{l}\text { DC low } \\
\text { IC low }\end{array}$ & DC high & DC 1ow & IC high & IC low & Overa11 \\
\hline $\mathrm{N}$ & & 6 & 6 & 6 & 6 & 12 & 12 & 12 & 12 & 24 \\
\hline \multirow[t]{2}{*}{ Position A } & $\overline{\mathrm{x}}$ & 1.824 & 1.813 & 1.754 & 1.853 & 1.818 & 1.803 & 1.784 & 1.833 & 1.811 \\
\hline & $\mathrm{s}$ & 0.171 & 0.062 & 0.141 & 0.108 & 0.123 & 0.131 & 0.154 & 0.087 & 0.124 \\
\hline \multirow[t]{2}{*}{ Position B } & $\overline{\mathrm{x}}$ & 1.566 & 1.772 & 1.738 & 1.795 & 1.669 & 1.766 & 1.652 & 1.784 & 1.718 \\
\hline & $\mathrm{S}$ & 0.626 & 0.084 & 0.130 & 0.098 & 0.439 & 0.114 & 0.440 & 0.088 & 0.318 \\
\hline \multirow[t]{2}{*}{ Position C } & $\bar{x}$ & 1.334 & 1.745 & 1.782 & 1.588 & 1.540 & 1.685 & 1.558 & 1.667 & 1.612 \\
\hline & $\mathrm{S}$ & 0.873 & 0.176 & 0.098 & 0.680 & 0.638 & 0.474 & 0.637 & 0.481 & 0.555 \\
\hline \multirow[t]{2}{*}{ Position D } & $\overline{\mathrm{x}}$ & 1.758 & 1.876 & 1.600 & 1.588 & 1.817 & 1.594 & 1.679 & 1.732 & 1.705 \\
\hline & $\mathrm{s}$ & 0.308 & 0.071 & 0.408 & 0.680 & 0.222 & 0.535 & 0.355 & 0.485 & 0.416 \\
\hline \multirow[t]{2}{*}{ Overa11 } & $\bar{x}$ & 1.620 & 1.802 & 1.718 & 1.706 & 1.711 & 1.712 & 1.669 & 1.754 & 1.712 \\
\hline & $\mathrm{s}$ & 0.562 & 0.113 & 0.227 & 0.470 & 0.411 & 0.365 & 0.427 & 0.341 & 0.387 \\
\hline
\end{tabular}


TABLE 10--Continued

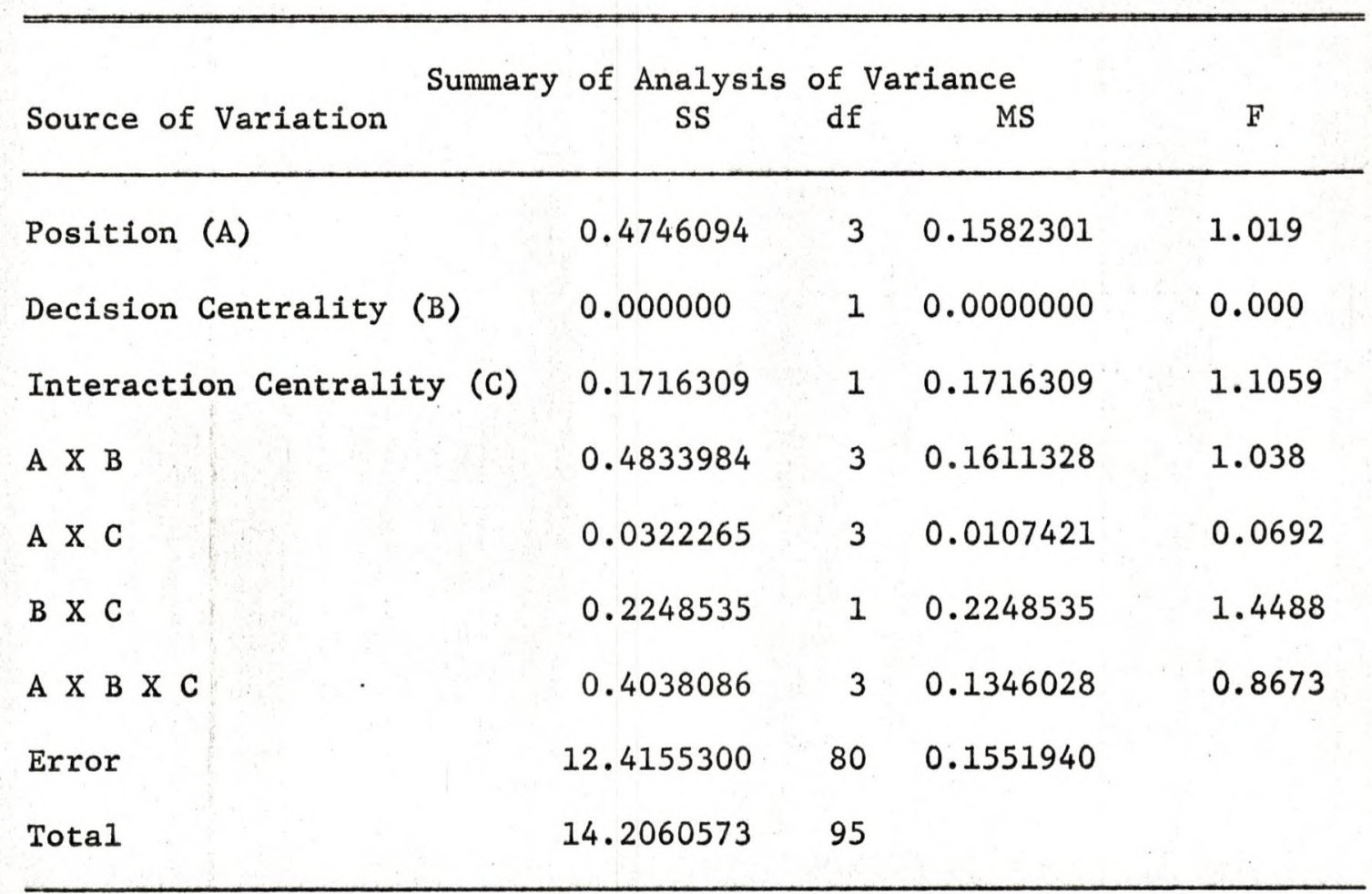


CHAPTER IV

\section{DISCUSSION}

The experimental treatment of a decision structure in past small group research has been virtually non-existent. At best, decision structure has been treated as an emergent phenomenon, one which occurs as people interact and find themselves under pressures for a group decision. While this sort of situation certainly has analogues in society, the analogues lie primarily in the relatively unstructured, informal domains of social interaction. In the more formal domains, including most complex organizations, problem solving groups do not wait on emergent decision structures before handling their problems.

The present research was an attempt to come to grips with some of the complexities of making decisions in small group problem solving. The framework not only departed from those of most past research, it also moved away from some relatively simple traditional assumptions about the nature of decision making in small groups. Throughout the literature of information theory, decision making, group problem solving, and computer simulation of group decision making, there has been the assumption that one, and perhaps the, primary factor in accurate decision making is the participants' reception of adequate information on which to base a group decision. If this condition is attained, the reasoning continues, an appropriate decision will usually be reached. However, when an appropriate decision was not reached, it has been 
assumed that this was due to human imperfection. The adequacy of the model was not questioned. The present research would suggest that the adequacy of the model might be questioned, and that attention to the organized conditions under which men make decisions may be as important as the presence of an adequate informational base for decision making.

The congruence model originated with an attempt to synthesize conflicting findings in past research. It was designed to extend and elaborate theoretical conceptions of group decision making in the solution of complex problems. Hypotheses were advanced which predicted that indices of both group process and objective and subjective outcomes would reflect the extent to which there was structural congruence between the conditions of decision and interaction centrality.

Summarized, the findings of the present study are as follows:

1. Indices of group process, time and number of information transactions to solution, reflect the congruence of the decision and interaction structures. These findings support a structural congruence model.

2. Indices of outcomes, i.e., problem solving accuracy, rated problem solving effectiveness, and satisfaction, do not reflect the congruence of the decision and interaction structures. These findings do not support a structural congruence model. However, neither do they support prevailing models of group problem solving.

3. In terms of problem solving accuracy, the present findings indicate that a decentralized decision structure will be most accurate. 
This supports the tentative findings of Hutte, and is clearly contradictory to the conclusions of Mulder. It also suggests that Shaw's earlier conclusions regarding the effectiveness of a spread interaction structure might be revised in terms of a decision structure.

4. The present findings indicate that Ss perceive their groups to be more effective at solving problems if they are operating within decision structures which are centralized. However, these groups are less accurate than those in which the decision structure is decentralized. In relative terms, one group is overestimating and the other group is underestimating its effectiveness. Past research has not examined these relationships.

5. Satisfaction in the present study conforms to findings in previous research. A decentralized interaction structure is more satisfying than a centralized interaction structure. No relationship was found between satisfaction and high or low decision centrality. The latter fails to confirm Maier and Hoffman's (1960) finding of a relationship between decision making power and satisfaction.

Traditionally there has been an association between the concepts of group structure and group process. The phrase, group structure and process, is not only a phrase, but also a conceptual link and a belief which is virtually imprinted on the minds of small group researchers. In a similar manner there has been a traditionally accepted belief that group process leads to outcome. While the present research supports the first belief, it raises questions about the latter, or at least the conditions under which it is accurate. That is, indices of group process support a congruence model. It 
does make a difference in group process if the decision and interaction structures are operating under similar or different conditions. However, the same cannot be said regarding outcomes. There, a decentralized decision structure is critical, at least in terms of accuracy and perceived effectiveness.

It is possible that group process is not necessarily related to outcome; or, that group process is related to outcome, however, not necessarily on the indices or under the conditions employed in this study.

Past research does not support either of the above possibilities with respect to time (Shaw, 1954a; Mulder, 1960). Time has been found to be related to accuracy, and the relationship has been one of less time per problem, with corresponding increases in accuracy. The present research raises questions both about this relationship, and the models within which it has been conceptualized and investigated in the past. Similarly, the number of messages to solution has been shown to decrease as accuracy increased (Mulder, 1960). Such was not the case here. The number of messages decreased with successive problems in groups which were structurally congruent (see Figure 6). Structurally incongruent groups showed a decrement through the second problem then a rise in the number of information transactions in the third problem. In absolute terms, the number of messages to solution in groups with centralized decision structures were fewer than the number of messages to solution in groups with decentralized decision structures. This might, in part, account for Mulder's findings. It remains, however, that there was an interaction between decision and 
interaction structures on this variable. Further, groups which were most accurate were not those with fewest total number of information transactions, as Mulder found, rather, accuracy was related to a higher overall number of communications.

The variables of time and number of messages to solution have traditionally been variables which have been inversely related to accuracy. The dissonant relationship between the present research and traditional findings may lie in previous conceptual models of small group problem solving not taking into account sufficient dimensions of the complexity of problem solving.

The lack of support for either the congruence model, or models used in previous research, with respect to the outcomes of accuracy and perceived accuracy raises problems. Mulder's work had suggested that earlier conceptualizations of decision making in small groups (e.g., that of Shaw) were theoretically inadequate. And, that research might be better designed in terms of an emergent decision structure, rather than focusing on the interaction structure. Mulder seemed to be asking if a centralized decision structure could not be emerging, even within a decentralized interaction structure.

However, Mulder's research did not attempt to systematically control or vary the nature of the decision structure. Rather, it seemed to be based on the assumption that, if left to its own devices, groups would produce an emergent decision structure. And, as this occurred, problem solving accuracy would improve. Conversely, if a decision structure did not emerge, problem solving accuracy would not improve, or at least, would not improve greatly. However, making 
comparisons between groups in which a decision structure emerged and groups in which a decision structure did not emerge, raises serious questions about the nature of the comparisons. That is, were the comparisons in Mulder's research being made between the presence or absence of emergent decision structures, or between groups which did or did not have certain unknown characteristics which led to the development of a decision structure? If, in the short period of time provided it, a group was unable to generate a decision structure in order to solve problems, it would seem to follow that that group might be relatively inaccurate in solving problems. Thus, Mulder's findings indicating the problem solving superiority of centralized decision structures might be reinterpreted to indicate only that centralized decision structures emerge within some groups. When these structures do emerge, the groups which develop them will show greater accuracy in problem solving than groups which do not generate decision structures.

While it may be true that an emergent, centralized decision structure is better than no emergent decision structure, the present research indicates clearly that a decentralized decision structure is more accurate than a centralized decision structure.

The present findings regarding subjects perceived effectiveness of their groups' problem solving contrasts sharply with reality, the latter defined in terms of the known accuracy of the groups (see Figure 8). It is possible that this finding is in some way related to the type of decision structure which emerged in Mulder's research. That is, if people believe a centralized decision structure will be more effective than a decentralized structure, and they are placed 
in an unstructured situation and told to solve problems as rapidly as possible, it would seem reasonable that a centralized decision structure might emerge. Whether this is the most accurate form of decision structure which could emerge is another question. The present data would suggest that it is not.

Questions regarding why the accuracy findings did not correspond with indices of group process might also be raised. Possible answers may lie in the lack of control which previous researchers have placed on decision making structures in small groups. The present research indicates that the decision structure, and the surrounding beliefs about what is an effective decision structure, is probably an important, but certainly neglected, variable in virtually all previous problem solving research. This raises the possibility that if many of the problem solving studies upon which our present fund of information is built were to be repeated, including controls for a decision structure, the results in some cases might not conform to previous findings.

Finally, neither do the findings regarding satisfaction conform to the congruence model. For most subjects, satisfaction appeared to be a simple function of the freedom of interaction. Again, these findings do not conform to indices of group process; satisfaction does not appear to be dependent upon congruence of decision and interaction structures. This finding might be altered, however, if controls were added for subject variables. For example, persons with high needs for power might respond quite differently to various combinations of decision and interaction structures than would persons with high needs for 
affiliation. Schacter (1959) has noted that volunteers for psychology experiments tend to be higher in needs for affiliation than nonvolunteers. The present Ss were volunteers, and possibly were responding to the openness of the respective interaction nets in terms of their needs for affiliation. This would account for the present findings regarding satisfaction in centralized and decentralized interaction structures. Given the possibility that certain complex organizations tend to attract, retain, and promote into high level decision making groups, persons who possess certain personality traits, this dimension takes on considerable significance for future research. Based on the findings of this study, it might be generally predicted that a group which contains a decentralized decision structure will be more accurate in solving complex problems than a group with a centralized decision structure. This group will be neither the most rapid nor perform the task in the fewest number of information transactions. If the dimension of a decentralized interaction structure is added to this group, the participants will, in all probability, like their task more than if the interaction structure is relatively centralized. The Ss will bring into the group setting certain pressures and preferences for a centralized decision structure. If allowed a choice, a centralized decision structure will probably be the result. However, such a choice will lead to a relatively inaccurate performance:

Complex organizations, e.g., governmental bureaucracies, corporations, the Armed Forces, perhaps more frequently than not will be found to operate under some form of a centralized decision 
structure. Western society seems to socialize its members in the belief that some one person is to be responsible for the actions of virtually any group. Consequently, decision systems and the distribution of social power are constructed and arranged to reflect this belief. This study raises serious questions about the practical effectiveness of this belief and practice, at least under certain conditions, and suggests that to the extent that all group members are involved in the decision making process and possess real decision power, more effective checks and balances will be instituted. These will lead to more accurate decisions.

Whether a congruence model, built upon relative centrality of decision and interaction structures, is the most appropriate model within which to conceptualize numerous dimensions of small group problem solving is an open question. Support was found for the model in dimensions of group rpocess, but not for outcomes. This led to questions being raised regarding the extent to which a simple, relatively global, model of small group problem solving has been an accurate reflection of reality. At the minimum this research indicates the need for independent treatment of decision and interaction structures, and their respective degrees of centrality, on indices of group process and problem solving outcomes. Further, this research raises questions about a rather lage number of past findings in which conclusions were drawn regarding decision making within varying interaction structures, but which did not in any systematic manner control for the nature of the decision structure. Future attempts to understand the conditions and dynamics of organized decision making systems should give consideration to these factors. 
APPENDIX 
ORIGINAL DATA, NUMBER OF INFORMATION TRANSACTIONS TO SOLUTION, TYPE OF GROUP STRUCTURE BY POSITION (CORRESPONDS TO TABLE 2)

\begin{tabular}{|c|c|c|c|c|c|c|c|c|c|c|}
\hline Position & $\begin{array}{l}\text { Decision } \\
\text { Centrality }\end{array}$ & $\begin{array}{l}\text { Interaction } \\
\text { Centrality }\end{array}$ & $\begin{array}{c}\text { Group } \\
1\end{array}$ & 2 & 3 & 4 & 5 & 6 & $\bar{x}$ & $\mathrm{~S}$ \\
\hline A & high & high & 115 & 131 & 51 & 80 & 39 & 291 & 117.83 & 91.96 \\
\hline A & high & low & 157 & -128 & 92 & 59 & 98 & 89 & 103.83 & 34.10 \\
\hline A & low & high & 260 & 403 & 382 & 132 & 143 & 204 & 254.00 & 116.90 \\
\hline A & 1ow & low & 118 & 100 & 156 & 136 & 99 & 304 & 152.17 & 77.52 \\
\hline B & high & high & 48 & 38 & 11 & 27 & 9 & 111 & 40.67 & 37.62 \\
\hline B & high & low & 128 & 111 & 55 & 48 & 77 & 47 & 77.67 & 34.58 \\
\hline B & low & high & 93 & 138 & 130 & 68 & 42 & 92 & 93.83 & 36.38 \\
\hline B & low & 1ow & 136 & 114 & 125 & 133 & 79 & 232 & 136.50 & 51.14 \\
\hline C & high & high & 23 & 51 & 18 & 29 & 16 & 111 & 41.33 & 36.39 \\
\hline C & high & low & 118 & 113 & 72 & 41 & 102 & 60 & 84.33 & 31.27 \\
\hline C & 1ow & high & 86 & 163 & 127 & 118 & 47 & 66 & 101.17 & 42.84 \\
\hline $\mathrm{C}$ & 1ow & low & 151 & 126 & 111 & 109 & 98 & 272 & 144.50 & 65.09 \\
\hline D & high & high & 66 & 42 & 12 & 24 & 14 & 69 & 37.83 & 25.33 \\
\hline D & high & low & 119 & 102 & 71 & 52 & 95 & 72 & 85.17 & 24.49 \\
\hline D & low & high & 77 & 96 & 115 & 40 & 52 & 42 & 70.33 & 30.85 \\
\hline $\mathrm{D}$ & low & low & 125 & 98 & 152 & 84 & 84 & 318 & 143.50 & 89.46 \\
\hline
\end{tabular}


ORIGINAL DATA, NUMBER OF INFORMATION TRANSACTIONS TO SOLUTION, TYPE OF GROUP STRUCTURE BY POSITION (CORRESPONDS TO TABLE 3)

\begin{tabular}{|c|c|c|c|c|c|c|c|c|c|c|}
\hline Problem & $\begin{array}{l}\text { Decision } \\
\text { Centrality }\end{array}$ & $\begin{array}{l}\text { Interaction } \\
\text { Centrality }\end{array}$ & $\begin{array}{c}\text { Group } \\
1\end{array}$ & 2 & 3 & 4 & 5 & 6 & $\bar{x}$ & $S$ \\
\hline 1 & high & high & 128 & 88 & 52 & 54 & 50 & 88 & 76.67 & 30.74 \\
\hline 1 & high & low & 226 & 124 & 84 & 86 & 170 & 96 & 131.00 & 56.66 \\
\hline 1 & low & high & 254 & 244 & 264 & 262 & 96 & 226 & 224.33 & 64.39 \\
\hline 1 & 1ow & low & 241 & 232 & 262 & 256 & 146 & 292 & 238.17 & 49.65 \\
\hline 2 & high & high & 52 & 134 & 24 & 58 & 12 & 290 & 95.00 & 104.59 \\
\hline 2 & high & low & 166 & 168 & 102 & 56 & 70 & 80 & 107.00 & 48.84 \\
\hline 2 & 1ow & high & 128 & 254 & 138 & 102 & 92 & 90 & 134.00 & 61.93 \\
\hline 2 & low & low & 162 & 90 & 172 & 88 & 116 & 368 & 166.00 & 105.09 \\
\hline 3 & high & high & 72 & 40 & 26 & 48 & 16 & 204 & 67.67 & 69.52 \\
\hline 3 & high & low & 130 & 162 & 104 & 48 & 122 & 92 & 109.67 & 38.60 \\
\hline 3 & low & high & 134 & 262 & 352 & 94 & 96 & 88 & 171.00 & 110.32 \\
\hline 3 & low & low & 126 & 116 & 110 & 118 & 98 & 466 & 172.33 & 144.17 \\
\hline
\end{tabular}


ORIGINAL DATA, TIME (IN SECONDS) TO SOLUTION, TYPE OF GROUP STRUCTURE BY PROBLEM (CORRESPONDS TO TABLE 4)

\begin{tabular}{|c|c|c|c|c|c|c|c|c|c|c|}
\hline Problem & $\begin{array}{l}\text { Decision } \\
\text { Centrality }\end{array}$ & $\begin{array}{l}\text { Interaction } \\
\text { Centrality }\end{array}$ & $\begin{array}{c}\text { Group } \\
1\end{array}$ & 2 & 3 & 4 & 5 & 6 & $\overline{\mathrm{x}}$ & $S$ \\
\hline 1 & high & high & 824 & 837 & 435 & 779 & 460 & 600 & 655.83 & 182.49 \\
\hline 1 & high & low & 2119 & 750 & 772 & 499 & 1218 & . 487 & 974.17 & 620.38 \\
\hline 1 & low & high & 2384 & 1490 & 1536 & 2206 & 868 & 1417 & 1650.17 & 557.19 \\
\hline 1 & low & low & 1069 & 1088 & 1472 & 1208 & 899 & 2163 & 1316.50 & 456.13 \\
\hline 2 & high & high & 315 & 832 & 240 & 519 & 191 & 1428 & 587.50 & 473.95 \\
\hline 2 & high & low & 1082 & 798 & 349 & 295 & 451 & 340 & 552.50 & 317.43 \\
\hline 2 & low & high & 2115 & 1404 & 833 & 752 & 683 & 786 & 1095.50 & 563.45 \\
\hline 2 & low & low & 694 & 442 & 880 & 662 & 709 & 1914 & 883.50 & 523.89 \\
\hline 3 & high & high & 692 & 284 & 214 & 399 & 315 & 710 & 435.67 & 214.01 \\
\hline 3 & high & 1ow & 680 & 706 & 351 & 272 & 706 & 364 & 513.17 & 204.41 \\
\hline 3 & low & high & 985 & 1517 & 1720 & 330 & 584 & 1153 & 1048.17 & 532.42 \\
\hline 3 & low & low & 527 & 550 & 489 & 690 & 481 & 2558 & 882.50 & 824.30 \\
\hline
\end{tabular}


ORIGINAL DATA, RATED PROBLEM SOLVING EFFECTIVENESS BY TYPE OF GROUP STRUCTURE (CORRESPONDS TO TABLE 7) 2

\begin{tabular}{llcccccccc}
\hline \hline $\begin{array}{l}\text { Decision } \\
\text { Centrality }\end{array}$ & $\begin{array}{l}\text { Interaction } \\
\text { Centrality }\end{array}$ & $\begin{array}{c}\text { Group } \\
1\end{array}$ & 2 & 3 & 4 & 5 & 6 & $\overline{\mathrm{X}}$ & $\mathrm{S}$ \\
\hline high & high & 94.00 & 73.75 & 70.00 & 51.25 & 60.50 & 75.75 & 70.88 & 14.56 \\
high & low & 63.50 & 42.25 & 74.50 & 72.25 & 57.25 & 83.25 & 65.50 & 14.52 \\
low & high & 68.50 & 27.75 & 76.75 & 36.00 & 53.50 & 45.00 & 51.25 & 18.85 \\
low & low & 61.25 & 55.75 & 69.00 & 45.75 & 75.50 & 21.00 & 54.71 & 19.48 \\
\hline
\end{tabular}

2 Because of zero values, a constant of 1 was added to each raw score before the $10 \mathrm{~g}$ transformation and the analysis of variance. 
ORIGINAL DATA, RATED PROBLEM SOLVING EFFECTIVENESS, TYPE OF GROUP STRUCTURE BY POSITION (CORRESPONDS TO TABLE 8) ${ }^{3}$

\begin{tabular}{|c|c|c|c|c|c|c|c|c|c|c|}
\hline Position & $\begin{array}{l}\text { Decision } \\
\text { Centrality }\end{array}$ & $\begin{array}{l}\text { Interaction } \\
\text { Centrality }\end{array}$ & $\begin{array}{c}\text { Group } \\
1\end{array}$ & 2 & 3 & 4 & 5 & 6 & $\overline{\mathrm{x}}$ & $\mathrm{s}$ \\
\hline A & high & high & 100 & 50 & 49 & 52 & 78 & 94 & 70.50 & 23.25 \\
\hline A & high & 1ow & 38 & 50 & 77 & 89 & 61 & 78 & 65.50 & 19.27 \\
\hline A & low & high & 61 & 5 & 84 & 92 & 37 & 22 & 50.17 & 34.69 \\
\hline A & 1ow & low & 56 & 71 & 82 & 100 & 50 & 79 & 73.00 & 18.26 \\
\hline B & high & high & 88 & 79 & 95 & 50 & 63 & 73 & 74.67 & 16.48 \\
\hline B & high & low & 70 & 48 & 50 & 62 & 73 & 87 & 65.00 & 14.80 \\
\hline B & low & high & 50 & 25 & 96 & 29 & 50 & 87 & 56.17 & 29.40 \\
\hline B & low & 1ow & 60 & 59 & 53 & 62 & 82 & 2 & 53.00 & 26.86 \\
\hline C & high & high & 93 & 90 & 86 & 3 & 5 & 68 & 57.50 & 42.34 \\
\hline C & high & low & 50 & 3 & 51 & 50 & 25 & 29 & 47.67 & 30.32 \\
\hline C & low & high & 67 & 74 & 64 & 21 & 77 & 71 & 62.33 & 20.78 \\
\hline $\mathrm{C}$ & low & low & 68 & 51 & 61 & 79 & 78 & 0 & 56.17 & 29.47 \\
\hline D & high & high & 85 & 76 & 50 & 100 & 96 & 68 & 79.17 & 18.64 \\
\hline D & high & low & 96 & 68 & 90 & 88 & 71 & 90 & 83.83 & 11.46 \\
\hline D & low & high & 96 & 7 & 63 & 2 & 50 & 0 & 36.33 & 39.54 \\
\hline D & low & low & 61 & 42 & 80 & 22 & 92 & 3 & 50.00 & 34.18 \\
\hline
\end{tabular}

3 Because of zero values, a constant of 1 was added to each raw score before the $10 \mathrm{~g}$ transformation and the analysis of variance. 
ORIGINAL DATA, RATED SATISFACTION, TYPE OF GROUP STRUCTURE BY PROBLEM (CORRESPONDS TO TABLE 9)

\begin{tabular}{|c|c|c|c|c|c|c|c|c|c|c|}
\hline Problem & $\begin{array}{l}\text { Decision } \\
\text { Centrality }\end{array}$ & $\begin{array}{l}\text { Interaction } \\
\text { Centrality }\end{array}$ & $\begin{array}{c}\text { Group } \\
1\end{array}$ & 2 & 3 & 4 & 5 & 6 & $\overline{\mathrm{x}}$ & $S$ \\
\hline 1 & high & high & 72.00 & 38.75 & 55.25 & 36.75 & 57.00 & 51.00 & 51.87 & 12.99 \\
\hline 1 & high & low & 61.00 & 44.25 & 72.50 & 75.50 & 39.75 & 76.00 & 61.50 & 16.11 \\
\hline 1 & low & high & 48.00 & 71.75 & 81.00 & 21.75 & 40.00 & 52.25 & 52.46 & 21.47 \\
\hline 1 & low & low & 71.25 & 76.25 & 48.25 & 73.75 & 84.25 & 58.75 & 68.75 & 13.02 \\
\hline 2 & high & high & 82.25 & 75.00 & 56.25 & 45.00 & 57.00 & 53.50 & 61.50 & 14.12 \\
\hline 2 & high & low & 82.50 & 46.25 & 83.00 & 80.50 & 77.00 & 80.50 & 74.96 & 14.22 \\
\hline 2 & 1ow & high & 73.75 & 63.25 & 77.50 & 53.50 & 42.50 & 78.75 & 64.87 & 14.58 \\
\hline 2 & low & low & 74.00 & 78.50 & 85.75 & 70.00 & 83.00 & 47.00 & 73.04 & 13.99 \\
\hline 3 & high & high & 81.75 & 82.25 & 62.00 & 23.50 & 57.50 & 96.00 & 67.17 & 25.68 \\
\hline 3 & high & low & 22.75 & 62.00 & 73.25 & 73.00 & 75.00 & 90.75 & 66.12 & 23.16 \\
\hline 3 & 1ow & high & 65.75 & 31.25 & 61.25 & 51.50 & 54.75 & 70.75 & 55.87 & 13.96 \\
\hline 3 & low & low & 84.75 & 59.75 & 70.00 & 48.50 & 74.25 & 34.50 & 61.96 & 18.30 \\
\hline
\end{tabular}


ORIGINAL DATA, RATED SATISFACTION, TYPE OF GROUP STRUCTURE BY POSITION (CORRESPONDS TO TABLE 10)

\begin{tabular}{|c|c|c|c|c|c|c|c|c|c|c|}
\hline Position & $\begin{array}{l}\text { Decision } \\
\text { Centrality }\end{array}$ & $\begin{array}{l}\text { Interaction } \\
\text { Centrality }\end{array}$ & $\begin{array}{l}\text { Group } \\
1\end{array}$ & 2 & 3 & 4 & 5 & 6 & $\bar{x}$ & $\mathrm{~S}$ \\
\hline A & high & high & 100.00 & 65.33 & 34.66 & 53.00 & 81.33 & 89.66 & 70.66 & 24.38 \\
\hline $\mathrm{A}$ & high & low & 63.00 & 51.00 & 70.66 & 78.33 & 63.33 & 66.66 & 65.50 & 9.10 \\
\hline $\mathrm{A}$ & low & high & 76.33 & 40.33 & 72.00 & 67.33 & 35.33 & 63.00 & 59.05 & 17.11 \\
\hline A & low & low & 69.66 & 70.33 & 77.66 & 91.66 & 45.00 & 84.00 & 73.05 & 16.08 \\
\hline B & high & high & 71.33 & 61.00 & 89.00 & 2.00 & 49.00 & 65.66 & 56.33 & 29.69 \\
\hline B & high & low & 50.00 & 49.66 & 65.66 & 73.66 & 72.33 & 49.66 & 60.16 & 11.70 \\
\hline B & 1ow & high & 41.33 & 96.33 & 49.33 & 47.33 & 48.66 & 59.00 & 57.00 & 20.09 \\
\hline B & low & low & 68.33 & 59.66 & 53.00 & 56.66 & 94.00 & 51.33 & 63.83 & 15.95 \\
\hline $\mathrm{C}$ & high & high & 83.33 & 59.00 & 93.66 & 2.00 & 1.33 & 82.00 & 53.55 & 41.76 \\
\hline C & high & low & 42.00 & 31.00 & 81.66 & 63.00 & 49.66 & 89.33 & 59.44 & 22.84 \\
\hline C & low & high & 58.66 & 63.33 & 73.00 & 46.33 & 48.00 & 82.00 & 61.89 & 13.97 \\
\hline C & low & low & 100.00 & 58.00 & 74.00 & 50.33 & 94.00 & 1.66 & 63.00 & 35.77 \\
\hline $\mathrm{D}$ & high & high & 60.00 & 76.00 & 14.00 & 83.33 & 97.00 & 68.33 & 66.44 & 28.65 \\
\hline D & high & low & 64.66 & 71.66 & 65.00 & 90.33 & 70.66 & 94.00 & 76.05 & 12.85 \\
\hline D & low & high & 73.33 & 21.66 & 98.33 & 8.00 & 49.00 & 65.00 & 52.55 & 33.57 \\
\hline D & low & low & 100.00 & 58.00 & 74.00 & 50.33 & 94.00 & 1.66 & 63.00 & 35.77 \\
\hline
\end{tabular}


REFERENCES 


\section{REFERENCES}

Adams, S. Status congruency as a variable in small group performance. Social Forces, 1953, 32, 16-22.

Bales, R. F. Interaction process analysis. Cambridge, Mass.: AddisonWesley, 1950.

Bales, R. F. Adaptive and integrative changes as sources of strain in social systems. In A. P. Hare, E. F. Borgatta, and R. F. Bales (Eds.), Small groups: Studies in social interaction. New York: Knopf, 1955, 127-131.

Bales, R. F. Task status and likeability as a function of talking and listening in decision-making group. In L. D. White (Ed.), The state of the social sciences. Chicago: University of Chicago Press, 1956, 148-161.

Bales, R. F. Task roles and social roles in problem solving groups. In E. E. Maccoby, T. M. Newcomb, and E. L. Hartley (Eds.), Readings in social psychology. (3rd ed.) New York: Holt, Rinehart and Winston, 1958, 396-413.

Bales, R. F., \& Slater, P. E. Role differentiation in small decisionmaking groups. In T. Parson, R. F. Bales, et al., The family, socialization, and interaction process. Glencoe, III.: Free Press, 1955, 259-306.

Bavelas, A. A mathematical model for group structures. Applied Anthropology, 1948, 7, 16-30.

Bavelas, A. Communication patterns in task-oriented groups. Journal of Accoustical Society of America, 1950, 22, 725-730.

Borgatta, E. F., \& Bales, R. F. Sociometric status patterns and characteristics of interaction. Journal of Social Psychology, 1956, 43, 289-297.

Burgess, R. I. An experimental and mathematical analysis of group behavior within restricted networks. Journal of Experimental and Social Psychology, 1968, 4, 338-349.

Christie, I. S., Luce, R. D., \& Macy, J., Jr. Communication and learning in task-oriented groups. Technical Report No. 231, Research Laboratory of Electronics, MIT, 1952. 
Cohen, A. M., Bennis, W. G., \& Wolkon, G. H. The effects of continued practice on the behaviors of problem-solving groups. Sociometry, 1961, 24, 416-432.

Cohen, A. M., Bennis, W. G., \& Wolkon, G. H. Changing small-group communication networks. Administrative Science Quarterly, 1962, 6, 443-462.

Exline, R. V., \& Ziller, B. C. Status congruency and interpersonal conflict in decision-making groups. Human Relations, 1959, 12, 147-162.

Festinger, L. A theory of cognitive dissonance. Evanston, Ill.: Row, Peterson, 1957.

Gilchrist, J. C., Shaw, M. E., \& Walker, I. C. Some effects of unequal distribution of information in a wheel group structure. Journal of Abnormal and Social Psychology, 1954, 49, 554-556.

Guetzkow, H., \& Dill, W. R. Factors in the organizational development of task oriented groups. Sociometry, 1957, 20, 175-204.

Guetzkow, H., \& Simon, H. A. The impact of certain communication nets upon organization and performance in task-oriented groups. Management Science, 1955, 233-250.

Heider, F. Attitudes and cognitive organization. Journal of Psychology, $1946,21,107-112$.

Heise, G., \& Miller, G. Problem solving by small groups using various communication nets. In A. P. Hare, E. F. Borgatta, and R. F. Bales (Eds.), Small groups: Studies in social interaction. New York: Alfred A. Knopf, 1955, 353-367.

Hirota, K. Japan Journal of Psychology, 1953, 24, 105-113.

Homans, G. C. Social behavior: Its elementary forms. New York: Harcourt, Brace, and World, Inc., 1961.

Hutte, H. Decision-taking in a management game. Human Relations, 1965, $18,5-20$.

Jones, E. E., \& Gerard, H. B. Foundations of social psychology. New York: John Wiley and Sons, Inc., 1967.

Lawson, E. D. Reinforced and non-reinforced four-man communication nets. Psychological Reports, 1964a, 14, 287-296.

Lawson, E. D. Reinforcement in group problem-solving with arithmetic problems. Psychological Reports, 1964b, 14, 703-710. 
Leavitt, H. J. Some effects of certain communication patterns on group performance. Journal of Abnormal and Social Psychology, 1951, $46,38-50$.

Maier, N. R. F., \& Hoffman, L. R. Quality of first and second solutions in group problem solving. Journal of Applied Psychology, $1960, \underline{44}, 278-283$.

Maier, N. R. F., \& Hoffman, I. R. Group decision in England and the United States. Personnel Psychology, 1962, 15, 75-87.

Mulder, M. Group structure and performance. Acta Psychologica, 1959, 16, 356-402.

Mulder, M. Communication structure, decision structure and group performance. Sociometry, 1960, 23, 1-14.

Newcomb, T. M. An approach to the study of communicative acts. Psychological Review, 1953, 60, 393-404.

Osgood, C. E., \& Tannenbaum, P. H. The principle of congruity in the prediction of attitude change. Psychological Review, 1955, $\underline{62}, 42-55$.

Sampson, E. E. Status congruence and cognitive consistency. Sociometry, 1963, 26, 146-162.

Schacter, S. The psychology of affiliation. Stanford: Stanford University, 1959 .

Shaw, M. E. Group structure and the behavior of individuals in small groups. Journal of Psychology, 1954(a), 38, 139-149.

Shaw, M. E. Some effects of problem complexity upon problem solution efficiency in different communication nets. Journal of Experimental Psychology, $1954(\mathrm{~b}), 4$ 8, $211-217$.

Shaw, M. E. Communication networks. In L. Berkowitz (Ed.), Advances in experimental social psychology. New York: Academic Press, 1964, Pp. 111-147.

Shaw, M. E., \& Rothschild, G. H. Some effects of prolonged experience in communication nets. Journal of Applied Psychology, 1956, 40, 281-286.

Shaw, M. E., Rothschild, G. H., \& Strickland, J. F. Decision processes in communication nets. Journal of Abnormal and Social Psychology, $1957,54,323-330$.

Slater, P. E. Role differentiation in small groups. American Sociological Review, 1955, 20, 300-310. 